Check for updates

Cite this: J. Mater. Chem. B, 2020 8, 2216

Received 6th December 2019

Accepted 22nd January 2020

DOI: 10.1039/c9tb02767j

rsc.li/materials-b

\section{Gold nanoclusters for biomedical applications: toward in vivo studies}

\begin{abstract}
Estelle Porret, Xavier Le Guével* and Jean-Luc Coll (D)*
In parallel with the rapidly growing and widespread use of nanomedicine in the clinic, we are also witnessing the development of so-called theranostic agents that combine diagnostic and therapeutic properties. Among them, ultra-small gold nanoclusters (Au NCs) show promising potential due to their optical properties and activatable therapeutic activities under irradiation. Furthermore, due to their hydrodynamic diameter of smaller than $6 \mathrm{~nm}$ and unique biophysical properties, they also present intriguing behaviors in biological and physio-pathological environments. In this review, we aim to present the latest research studies published on such nanoparticles in animals. We also propose guidelines to identify the main physicochemical parameters that govern the behaviour of Au NCs after administration in small animals, notably concerning their renal elimination and their ability to accumulate in tumors. Then, we present recent advances in their use as theranostic agents putting them in parallel with other contrast agents.
\end{abstract}

\section{Introduction}

In the past few years, a new class of photoluminescent ultrasmall size metal nanoparticles (NPs) with a core size between 0.2 and $3 \mathrm{~nm}$ and usually referred to in the literature as nanoclusters $(\mathrm{NCs})^{1}$ have gained growing interest in biomedical applications. They are composed of an assembly of tens to

Université Grenoble Alpes - INSERM U1209 - CNRS UMR 5309,

38000 Grenoble, France. E-mail: Estelle.porret@univ-grenoble-alpes.fr,

Xavier.le-guevel@univ-grenoble-alpes.fr, Jean-luc.coll@univ-grenoble-alpes.fr

hundreds of metallic atoms (gold, silver, platinum, zinc, copper, etc.) (2-6 $^{2-6}$ stabilized by ligands (organic thiolate molecules, ${ }^{7-15}$ dendrimers, ${ }^{16-18}$ DNA, ${ }^{19,20}$ amino acids,${ }^{21-23}$ peptides ${ }^{24-26}$ or proteins ${ }^{27-29}$ ). NCs can be viewed as the missing link between metal-ligand complexes and plasmonic metal NPs.

Their optical and physicochemical properties are suitable for biomedical applications since:

- Their ultra-small size should favor renal elimination, but increase passive accumulation in the tumor micro-environment compared to small molecules. ${ }^{30}$

Dr Xavier Le Guevel obtained his

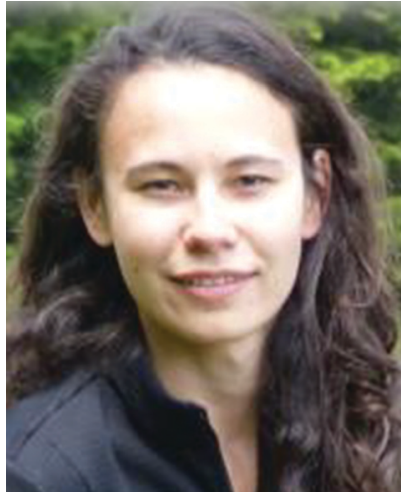

Estelle Porret
Dr Estelle Porret received her Chemistry and Physical Engineering degree, with specialization in nano- and microtechnology, from Graduate School of Chemistry, Biology and Physics (ENSCBP) and a Master's level degree in physical chemistry of materials from Bordeaux University in 2016. She joined Dr Jean-Luc Coll's group at the Institute for Advanced Biosciences the same year to obtain her $P h D$, focusing on the development of novel gold nanoclusters for cancer diagnosis and therapy.

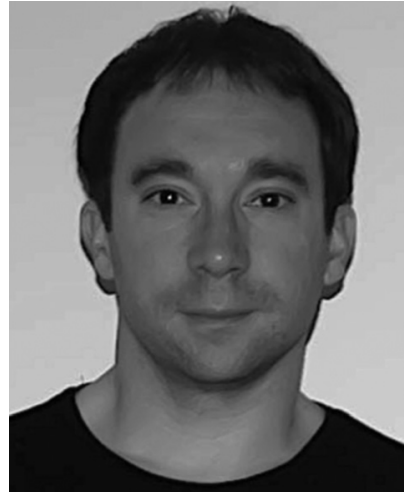

Xavier Le Guével
$P h D$ in 2006 in Chemistry from the University of Tours (France). Following this, he did some postdoctoral fellowships in physics (Rome, Italy), biophotonics (Dublin, Ireland) and biotechnology (Saarbruecken, Germany) between 2006 and 2010 before starting as an independent researcher at the Nanomedicine Centre Bionand in Malaga (Spain). Since 2016, XLG has been a CNRS researcher at the Institute for Advanced Biosciences in Grenoble (France). His work focuses on the development of new nanomaterials such as metal nanoclusters and optical instruments for medical applications and more specifically for cancer treatment and diagnosis from fundamental research to pre-clinical application. 
- They can be detected in vivo by multimodal imaging techniques owing to their tunable photoluminescence (PL), from the ultra-violet (UV) to near-infrared (NIR) region ${ }^{17}$ and by X-ray $\mathrm{CT}^{31,32}$ or, as recently detected, by photoacoustic imaging $^{33}$ owing to their metallic composition.

- They can be used as radio-sensitizers ${ }^{34-36}$ due to the electronic properties of metal NCs.

- They can be used as delivery systems. ${ }^{37-39}$

Gold is often preferred over other metals for biomedical applications because of its biocompatibility and inertness. Therefore, we mainly focus this review on the in vivo studies of gold NCs (Au NCs).

\section{Design of Au NCs}

\subsection{Synthesis parameters}

$\mathrm{Au}$ NCs can be synthesized in solution by the classical "bottomup" approach using metal precursors. Depending on the nature of the ligands and the synthesis parameters such as the metal:ligand:reducing agent proportion, $\mathrm{pH}$, temperature, or strength of reducing agents, a large library of Au NCs have been synthesized and used for in vivo studies. ${ }^{40}$ They can be divided into two main categories.

The first one corresponds to Au NCs with a discrete composition at the atomic level synthesized with thiolated molecules. These clusters are represented by their formula $\mathrm{M}_{n}(\mathrm{~L})_{m}$, where $n$ and $m$ are respectively the number of metal atoms (M) and ligands $\left(\mathrm{L}=\right.$ thiolate ligand $\mathrm{SR}^{31}$ or poly(amino-amide) $\mathrm{PAMAM}^{17}$ ).

Using this "bottom-up" approach, it was difficult to control the growth of single-size stable Au NCs and the final products

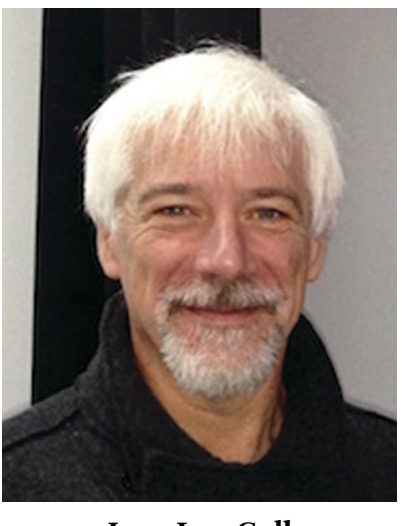

Jean-Luc Coll
Dr Jean-Luc Coll is the Director of Research at INSERM (Institut National de la Santé et de la Recherche Médicale) in France. $\mathrm{He}$ is in charge of the team "Cancer Targets and Experimental Therapeutics" in the Institute for Advanced Biosciences in Grenoble. JLC had an initial training in molecular biology (thesis in microbial genetics on E. coli), and then focused on cancer, first as a postdoc at the Burnham Institute (La Jolla USA) and then at the Cancer Research Center of Lyon (CRCL - Centre Léon Bérard). For the last 20 years, he has been working at the interfaces between biology, chemistry, physics and medicine with a clinical (veterinary and human) and industrial (2 Start-up) vision. $J L C$ is focused on the use of near-infrared labeled nanoparticles to target tumors, guide surgery and enhance radiotherapy, phototherapy or innovative therapies. In addition to the developments of nanovectors, he is also deeply involved in the generation of innovative adapted medical devices. were often composed of mixtures of Au NCs. Indeed, in 2004, the work of Tsukuda et al. ${ }^{24,41}$ on the characterization of gold NCs stabilized with glutathione (SG) $\left(\mathrm{Au}_{n} \mathrm{SG}_{m}\right)$, by polyacrylamide gel electrophoresis and electrospray ionization mass spectrometry, revealed the presence of nine species $\left(\mathrm{Au}_{10} \mathrm{SG}_{10}, \mathrm{Au}_{15} \mathrm{SG}_{13}, \mathrm{Au}_{18} \mathrm{SG}_{14}, \mathrm{Au}_{22} \mathrm{SG}_{16}, \mathrm{Au}_{22} \mathrm{SG}_{17}, \mathrm{Au}_{25} \mathrm{SG}_{18}\right.$, $\mathrm{Au}_{29} \mathrm{SG}_{20}, \mathrm{Au}_{33-35} \mathrm{SG}_{22}$, and $\mathrm{Au}_{38-39} \mathrm{SG}_{22}$ ). Furthermore, it was challenging to synthesize gram-scale monodispersed Au NCs. In 2007 , a so-called etching method was then proposed ${ }^{42}$ based on excess ligands with increasing temperature to obtain stable and single-size Au NCs. This process was first used to produce $\mathrm{Au}_{25} \mathrm{SG}_{18}$ on a large scale, ${ }^{43}$ prior to adopting a size-focusing methodology with the aim of extending the obtention of largescale monodispersed $\mathrm{Au}$ NCs to other sizes such as $\mathrm{Au}_{10} \mathrm{SG}_{10}$, $\mathrm{Au}_{15} \mathrm{SG}_{13}, \quad \mathrm{Au}_{18} \mathrm{SR}_{13} \quad\left(\mathrm{SR}=\mathrm{SG}, \quad \mathrm{S}-c-\mathrm{C}_{6} \mathrm{H}_{11}\right), \quad \mathrm{Au}_{38} \mathrm{SR}_{24}$ and $\mathrm{Au}_{144} \mathrm{SR}_{60},\left(\mathrm{SR}=\mathrm{SC}_{2} \mathrm{H}_{4} \mathrm{Ph}, \mathrm{SC}_{12} \mathrm{H}_{25}\right) \cdot{ }^{1,44-46}$ Recent reviews have summarized the advances in synthesis of Au NCs and their properties. ${ }^{44,47-49}$ Size focusing still has some limitations to obtain atomically precise Au NCs with some ligands. Au NCs stabilized with polyethylene glycol (PEG), ${ }^{15,50}$ zwitterions $(\mathrm{Zw})^{8,33}$ or proteins ("bovine serum albumin" BSA or transferrin) ${ }^{27,29}$ as ligands exhibit some polydispersity and correspond to the second category of Au NCs: subnanometer-scaled NPs with a core size between 1 and $3 \mathrm{~nm}^{.51}$

Metal NPs tend to aggregate in solutions over time due to ionic and electrostatic interactions (van der Waals forces)..$^{52}$ To reduce this effect, NPs can be stabilized with ligands in order to generate electrostatic or steric repulsions between the NPs. Thiolate ligands are usually used due to the strong bond between the sulfur group and the gold surface $\left(40 \mathrm{kcal} \mathrm{mol}^{-1}\right){ }^{53} \mathrm{~A}$ large library of biocompatible ligands such as proteins, ${ }^{27}$ DNA, ${ }^{19}$ peptides, ${ }^{24}$ dendrimers, ${ }^{17}$ polymers ${ }^{16}$ or small organic molecules following the previous criteria are suitable for stabilizing NCs. ${ }^{7}$

Lipoic acid (LA $)^{10,11,37,54}$ is an example of a bidentate thiol ligand with strong anchors onto the metal surface, and its carboxylic groups that are negatively charged at physiological $\mathrm{pH}$ are known to generate electrostatic repulsion between NCs. Following this, a large panel of zwitterions based on lipoic acid sulfobetaine (LA-sulfobetaine) for stabilizing Au NCs have been designed, which exhibited remarkable colloidal stability in various media with high antifouling effects. ${ }^{12,13,55}$ Indeed, F. Aldeek et al. $^{8}$ demonstrated that Au NCs stabilized by LA-sulfobetaine with a zwitterion moiety remained stable for at least 3 months even in acidic phosphate buffer ( $\mathrm{pH} 2)$ or in the presence of $0.25 \mathrm{M}$ antioxidant biomolecules. In contrast, $\mathrm{Au}$ NCs stabilized only by LA aggregated with time, which confirms the enhanced colloidal stability of zwitterionic functions. Another zwitterionic ligand widely used in NC synthesis is SG. ${ }^{26}$ This tripeptide is naturally present in eukaryotic cells to maintain their intracellular redox homeostasis. ${ }^{3} \mathrm{SG}$ was used to synthesize atomically precise $\mathrm{NC} \mathrm{Au}_{n} \mathrm{SG}_{m}$, negatively charged at physiological $\mathrm{pH}$, initiating the metal growth from the cysteine end of the peptide. ${ }^{41,42}$ Single amino acids, such as histidine ${ }^{23}$ and cysteine, ${ }^{21,22}$ which are positively charged and neutral at physiological $\mathrm{pH}$, respectively, have also been used to stabilize NCs. The use of longer sequences of amino acid will induce 
steric repulsion between the NCs. The first protein employed to grow NCs is the BSA. ${ }^{27}$ This $66.5 \mathrm{kDa}$ protein is composed of tyrosines that could reduce gold atoms under alkaline conditions $(\mathrm{pH} \sim 12),{ }^{56}$ and then be trapped by the thiol group of cysteines. Several studies reported the in vivo applications of AuBSA NCs. ${ }^{34,39,57-62}$ Following the same process, it was possible to grow $\mathrm{Au}$ NCs within transferrin, ${ }^{63}$ a protein that transports iron with receptors overexpressed at the surface of some cancer cells. ${ }^{64}$ NCs stabilized by transferrin and conjugated with graphene oxide have already been used in vivo. ${ }^{65}$ Finally, PEG is often used as a biocompatible capping agent to form a hydrating layer and generate steric hindrance between the NCs. ${ }^{8,13-15}$

\subsection{Specificities of the Au NCs for in vivo applications}

2.2.1 Ultra-small size. The two main elimination pathways of NPs from the body are the urinary and hepatic systems. The first one is often preferred because it is a quick filtration process from the blood through the kidneys to the bladder. More precisely, according to their different pore sizes, the NPs pass through the glomerular capillary walls into the endothelium (70-90 nm), the glomerular basement membrane (2-6 nm), and the podocyte $(4-11 \mathrm{~nm}) \cdot{ }^{35,45,46}$ The combined effects of these three layers have a fixed kidney filtration threshold (KFT) of around 6-8 $\mathrm{nm}$ for spherical NPs (Fig. 1). ${ }^{66,67}$ Spherical metal NPs with HD below 6-8 nm, around $40 \mathrm{kDa},{ }^{68}$ are thus expected to be eliminated by the kidneys. NPs with a larger HD are generally retained in the reticuloendothelial system (RES) through nonspecific uptake by specific macrophages of the liver (Kupffer cells) and the spleen due to the endothelial leakiness effect. Indeed, the liver is composed of non-continuous endothelial cells with vascular fenestration between 50 and $100 \mathrm{~nm}$ and the inter-endothelial cell slit of the spleen is between 200 and $500 \mathrm{~nm} .^{69}$ There are thus typical cut-off sizes that control the elimination and nonspecific storage of the NPs in the body.
A study was conducted to follow the biodistribution of $\mathrm{Au}$ and $\mathrm{Ag}$ NPs with sizes ranging between 1.4 and $250 \mathrm{~nm}$ after intravenous administration in mice. It confirmed the size-dependent toxicity of NPs. If small NPs were widely spread into the organs, larger ones were mainly found in the liver and spleen. ${ }^{70}$ The accumulation of metal NPs in different organs is considered a major issue due to their poor degradation that could induce acute toxicity. ${ }^{69,71}$ This size effect could be extended to other inorganic nanomaterials such as quantum dots, ${ }^{72}$ lanthanide NPs, ${ }^{73}$ and carbon nanotubes. ${ }^{74}$

A deeper toxicology study ${ }^{75}$ was carried out on Au NPs with sizes between 3 and $100 \mathrm{~nm}$ after their intraperitoneal injection in mice. Surprisingly, the smallest and largest NPs $(3,5,50$, and $100 \mathrm{~nm}$ ) did not show any harmful effects in mice, while those with intermediate sizes $(8,12,17$, and $37 \mathrm{~nm})$ induced severe sickness that can lead to premature death in mice. These studies revealed the potential toxicity of Au NPs larger than $6 \mathrm{~nm}$ and advantages of using ultra-small $\mathrm{Au}$ NCs.

2.2.2 Optical properties. Owing to their sub-nanometer diameter, Au NCs exhibit molecular-like properties such as discrete electronic states (HOMO-LUMO, highest occupied molecular orbital and lowest unoccupied molecular orbital), leading to photoluminescence (PL) properties tunable from the UV to the NIR. ${ }^{17}$ The PL has been attributed to complex and multiple energy transfers taking place in the metal core via metal-to-metal charge transfer (MMCT), and between the metal and the ligands via ligand-to-metal charge transfer (LMCT) or ligand-to-metal-metal charge transfer (LMMCT). The correlation between the structure of NCs and their optical properties is still not completely understood and we invite readers to refer to fully comprehensive reviews addressing this topic. ${ }^{51,76}$

Several $\mathrm{Au}$ NCs exhibit PL in the NIR window between 600 and $850 \mathrm{~nm} \cdot{ }^{14,21,77}$ Very recently, the spectral window has been extended to the shortwave infrared (SWIR) region $(900-1700 \mathrm{~nm}) .^{78}$ Developing biocompatible optical probes in the NIR/SWIR

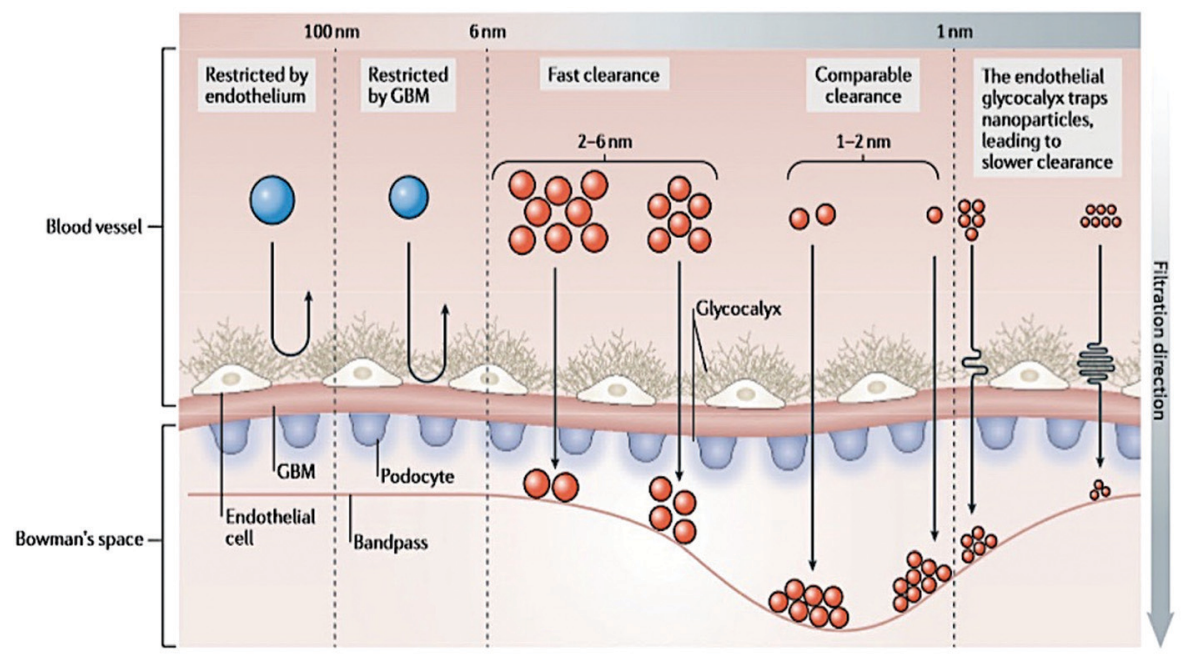

Fig. 1 Layer composition of the glomerular filtration barrier. The filtration takes place through the endothelial fenestrae, across the glomerular basement membrane and the pores between podocytes. The combination of these three layers defines the size of the compounds that could cross the glomerular filtration barrier. Reproduced from ref. 66 with permission from Springer Nature publishing group. 
optical window presents an advantage for in vivo imaging in deep tissues due to reduced auto-fluorescence, exponential decrease in light scattering and improved penetration of light into the tissues, offering potentially a higher spatial resolution. ${ }^{79} \mathrm{Au}$ NCs also present large Stokes shift in comparison to most of the organic fluorophores $\left(<20-30 \mathrm{~nm}^{80}\right)$, which can exceed $100 \mathrm{~nm} \cdot{ }^{81,82}$ This reduces the scattering and absorption of light and improves fluorescence detection.

The main limitation of atomically precise $\mathrm{Au}$ NCs as optical probes is related to their low quantum yield (QY) one order of magnitude lower than those of quantum dots, ${ }^{83}$ lanthanide NPs, ${ }^{84}$ and organic dyes ${ }^{85}$ especially in the NIR/SWIR windows. Most of the $\mathrm{Au}$ NCs exhibit a $\mathrm{QY}<1 \%$ with the well-characterized $\mathrm{Au}_{25} \mathrm{SG}_{18}$ exhibiting a QY $\sim 0.3 \%,{ }^{86}$ which is $10^{7}$ times higher than that of bulk gold. ${ }^{87}$ Fortunately, a few $\mathrm{Au}_{n} \mathrm{SG}_{m}$ exhibit higher QYs, such as $\mathrm{Au}_{18} \mathrm{SG}_{14}\left(\lambda_{\text {exc./em. }}=590 \mathrm{~nm} / 745 \mathrm{~nm}, \mathrm{QY} \sim 5.3 \%\right)^{88}$ or $\mathrm{Au}_{22} \mathrm{SG}_{18}\left(\lambda_{\text {exc. } / \mathrm{em} .}=520 \mathrm{~nm} / 665 \mathrm{~nm}, \mathrm{QY} \sim 8 \%\right) .{ }^{89}$ Different strategies have been reported to improve the brightness of Au NCs based on (i) doping with another metal, ${ }^{90-92}$ (ii) using ligands that can delocalize their electronic density to the gold core, ${ }^{93,94}$ or (iii) rigidification of the ligand shell surrounding the metal core. ${ }^{77,95,96}$
Therefore, it is crucial to develop new strategies to improve their QY. A first approach to enhance the brightness involves doping Au NCs with another metal. As an example, Rongchao Jin et al. obtained a QY of around $40 \%$ by doping Au NCs with 13 silver atoms ${ }^{90}$ (Fig. 2A). We also obtained a QY of around $15 \%$ by doping AuSG with silver. ${ }^{91}$ Similar results were obtained when doping Au NCs with $2 \%$ of different metals $(\mathrm{Ag}, \mathrm{Cu}, \mathrm{Pt}, \mathrm{Zn}$, and $\mathrm{Cd}) .{ }^{68} \mathrm{~A}$ second approach is based on the use of ligands that can delocalize their electronic density to the gold core. Replacing hexyl $\left(\mathrm{C}_{6} \mathrm{H}_{13}\right)$ by dodecyl $\left(\mathrm{C}_{12} \mathrm{H}_{25}\right)$ to stabilize $\mathrm{Au}_{25}$, or mixing $\mathrm{Au}_{25} \mathrm{SG}_{18}$ with a peptide nucleic acid (PNA) containing electron-rich atoms (e.g. O, N) induced a 2-3 fold enhancement of the $\mathrm{PL}^{93}$ (Fig. 2B). The exchange of some ligands of $\mathrm{Au}_{38}\left(\mathrm{SPhC}_{2}\right)_{24}$ by $\mathrm{HSPhNO}_{2}$ rather $\mathrm{SPhOCH}_{3}$ also induced an increase of the PL. ${ }^{94}$

A third strategy is based on blocking the loss of energy caused by intramolecular rotation of the ligand, by rigidifying the shell structure. Very bright fluorescent $\mathrm{Au}_{22} \mathrm{SG}_{18}(\mathrm{QY} \sim 62 \%$ in toluene, $\lambda_{\text {em. }}=630 \mathrm{~nm}$ ) was obtained after adding tetraoctylammonium cations while the initial NCs presented a $\mathrm{QY} \sim 7 \%$ (in water, $\left.\lambda_{\mathrm{em}}=665 \mathrm{~nm}\right)^{95}$ (Fig. 2C). A rigidification
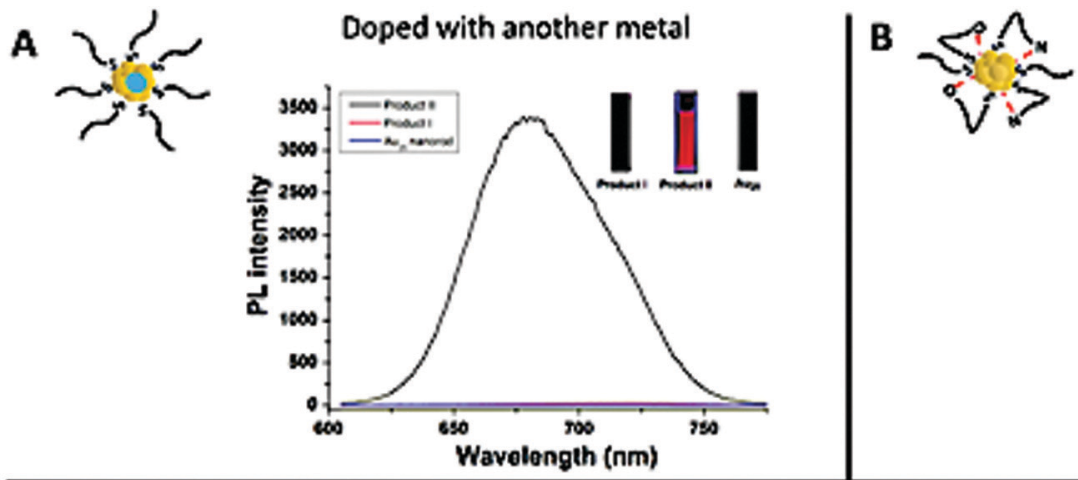

\section{Ligands with electron-rich atoms}

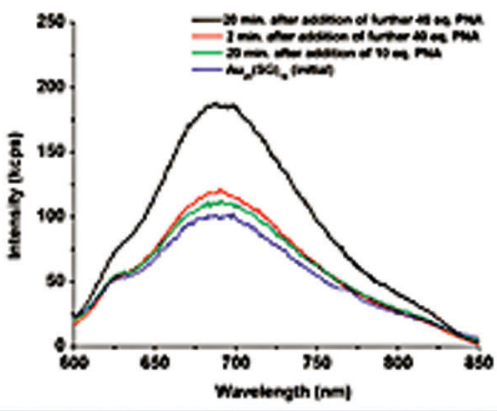

Aggregation Induced Enhancement
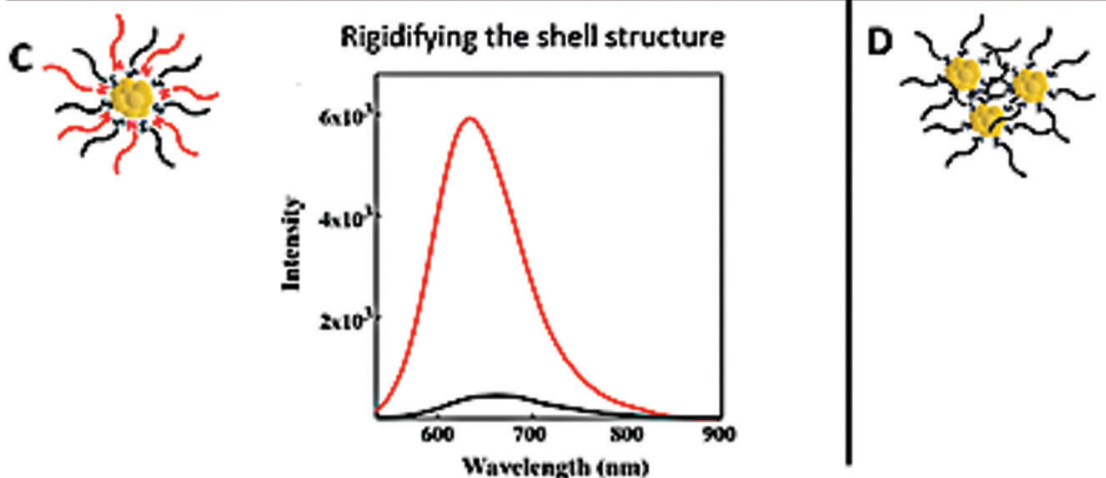

Fig. 2 Strategies to enhance the PL of the metal NCs. (A) Silver doping: Product I was obtained by reacting Au NPs with an Ag' thiolate complex, which gave rise to $\mathrm{Ag}_{x} \mathrm{Au}_{25-x} \mathrm{NCs}$ with a maximum of $12 \mathrm{Ag}$ atoms. Product II was obtained by reacting $\mathrm{Au}_{11} \mathrm{NCs}$ with the $\mathrm{Ag}$ 'thiolate complex, which gave rise to $\mathrm{Ag}_{13} \mathrm{Au}_{12} \mathrm{NCs}$. The PL spectra of $\mathrm{Au}_{25} \mathrm{NCs}$ (bottom, blue line), Product I (middle, red line), and Product II (top, black line) show that the number of silver atoms has a strong impact on the optical properties of the NCs. The inset presents the fluorescence emission of the solution of the corresponding products under UV illumination ( $\lambda_{\text {exc. }}=365 \mathrm{~nm}$ ). (B) LMCT: luminescence spectra of $\mathrm{Au}_{25} \mathrm{SG}_{18}$ (blue) and after the addition of different equivalents of an electron-rich atom, PNA (initial concentration of $\mathrm{Au}_{25} \mathrm{SG}_{18}: 1.1 \mu \mathrm{M}, \mathrm{OD}_{614} \sim 0.025, \lambda_{\text {exc. }}=514 \mathrm{~nm}$ ). (C) Rigidification of the shell: luminescence spectra of $\mathrm{Au}_{22} \mathrm{SG}_{18}$ (black) and after the addition of tetraoctylammonium cations (red) into toluene to rigidify the shell of ligands $\left(\mathrm{OD}_{514} \sim 0.025, \lambda_{\text {exc. }}=514 \mathrm{~nm}\right)$. (D) AIE effect: excitation and emission spectra at similar Au NC concentrations of AuSG (dashed lines) and after the addition of PAH to promote electrostatic cross-linking between Au NCs (PAH-AuSG, solid lines). The inset presents the fluorescence emission of the solution of the corresponding products under UV illumination $\left(\lambda_{\text {exc. }}=366 \mathrm{~nm}\right.$ ). Reproduced with permission from John Wiley and Sons for (A) ref. 90, and American Chemical Society for (B) ref. 93 and 94, (C) ref. 95, and (D) ref. 97. 
of the shell structure of $\mathrm{Au}$ NCs stabilized with 6-aza2thiothymine (ATT) was also obtained by adding L-arginine $\left(\mathrm{QY} \sim 65 \%\right.$, versus $\mathrm{QY} \sim 1.8 \%$ for the NCs alone; $\lambda_{\mathrm{em}}=$ $530 \mathrm{~nm}) .{ }^{96}$ It is also possible to rigidify the shell by creating a second layer and a PL enhancement of 300 was observed when the ratio $\mathrm{Au}: \mathrm{Zw}$ passed from $1: 1$ to $1: 40 .^{77}$

Finally, the aggregation-induced enhancement effect ${ }^{98}$ can also be seen as a strategy to boost Au NC PL. Indeed, aggregation will create stronger intra- and inter-complex aurophilic $\mathrm{Au}(\mathrm{I}) \cdots \mathrm{Au}(\mathrm{I})$ interactions that could enhance the PL signal. At the same time, the intramolecular rotation and vibration of the ligands are reduced and the Au core is better protected from solvent molecules, thereby reducing the probability of nonradiative relaxation of the excited states. ${ }^{47,99}$ These two phenomena induce an enhancement of the emission of the NCs. By generating self-assembled AuSG using cationic polyelectrolytes such as poly(allylamine hydrochloride) (PAH), it was possible to control the distance between Au NCs by adjusting the $\mathrm{pH}$ and to increase the QY from 7 to almost $25 \%$ using the AIE effect ${ }^{97}$ (Fig. 2D).

2.2.3 Surface properties. Surface functionalization of $\mathrm{Au}$ NCs has been largely investigated and an extensive library of biocompatible ligands able to generate electrostatic repulsion such as small organic molecules, ${ }^{7-11}$ amino acids, ${ }^{21,22}$ and peptides $^{24-26}$ and/or steric repulsion such as proteins, ${ }^{27-29}$ DNA, ${ }^{19,20}$ and dendrimers, ${ }^{16-18}$ between NCs have been used.

For example, zwitterions based on lipoic acid sulfobetaine (LA-sulfobetaine), a bidentate thiol ligand with strong anchors to the metal surface, present remarkable colloidal stability in various media with high antifouling effects, ${ }^{8,13,100}$ while PEGylated ligands are often used as a biocompatible capping agent to form a hydrating layer and generate steric hindrance between the NCs. ${ }^{8,13-15}$

Other small organic molecules and biomolecules are also commonly used for functionalizing the NC surface:

- fluorophores to shift the optical properties of Au NCs toward the NIR region; ${ }^{23,62,101}$ drugs, photo or radiosensitizers for cancer therapy;

- targeting molecules to specifically interact with receptors overexpressed at the surface of tumor cells, such as:

- Folic acid (FA) that can recognize the folate receptors (FRs), overexpressed in many human cancer cells (ovary, breast, colon, kidneys, liver, testes, brain, lungs, and blood), ${ }^{54,61,101-103}$
- Luteinizing hormone-releasing hormone (LHRH) overexpressed in several types of cancer cells (ovary, breast, prostate, lungs, and liver), ${ }^{104}$

- Hyaluronic acid (HA) that can bind to CD44 receptors overexpressed at the surface of different cancer cells, in particular cancer stem cells, ${ }^{61}$

- AMD3100 that can interact with CXCR4, an up-regulating receptor, in particular in leukemia or breast cancer cells, ${ }^{105}$

- Cyclic RGD (cRGD), a zwitterionic compound capable of interacting with $\alpha_{\mathrm{v}} \beta_{3}, \alpha_{5} \beta_{1}$, and $\alpha_{\mathrm{v}} \beta_{5}$ integrins highly present in neoangiogenic endothelial cells and several solid tumors. ${ }^{106-108}$

Two main techniques can be used to functionalize the Au NCs with specific molecules. An efficient approach involves directly synthesizing Au NCs with the molecule of interest usually with a terminal thiol group that could bind to the metal surface. ${ }^{8,9}$ A second approach is based on the postfunctionalization of Au NCs. Click chemistry ${ }^{15}$ and succinimidyl ester $^{105,109,110}$ reactions have been used to covalently bind molecules of interest to the ligand stabilizing the Au NCs, ${ }^{15,54,101,107}$ or ligand exchange could be used if the molecule of interest has a thiol group. ${ }^{110}$

\section{Physico-chemical parameters affecting the biodistribution of Au NCs}

C. Zhou et al. ${ }^{111}$ studied the biodistribution of AuSG with NIR emission. The highest uptake of the AuSG in the kidneys $(21 \%$ of injected dose per gram of tissue, ID per g) was obtained at $5 \mathrm{~min}$ pi (post injection) and decreased almost by 3 fold (7.5 ID per g) after urinary excretion. These observations were consistent with their short circulation time in blood (half-life, $t_{1 / 2 \alpha} \sim 5 \mathrm{~min}$ ) and indicated that AuSG were mainly eliminated via the urinary system. The accumulation of AuSG in the liver and spleen was lower than that in the kidneys (respectively 4 and $2.4 \%$ ID per $\mathrm{g}$ ) and remained constant over time. After $48 \mathrm{~h}$, more than $50 \%$ of the injected AuSG were eliminated.

We obtained comparable results with AuZw, which presented a short blood circulation time $\left(t_{1 / 2 \alpha} \sim 6 \mathrm{~min}\right) .{ }^{112}$ Using laser-induced breakdown spectroscopy (LIBS), we detected a strong Au signal in the medulla of the kidneys $30 \mathrm{~min}$ pi that was almost undetectable at $1 \mathrm{~h}$ (Fig. 3A). In contrast, a low but
A

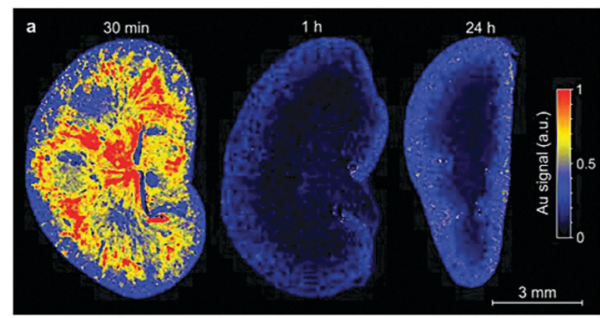

B

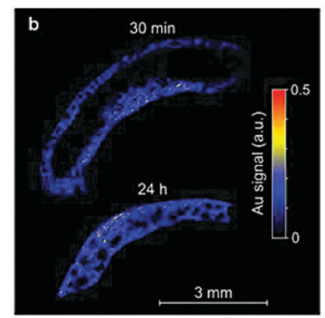

C

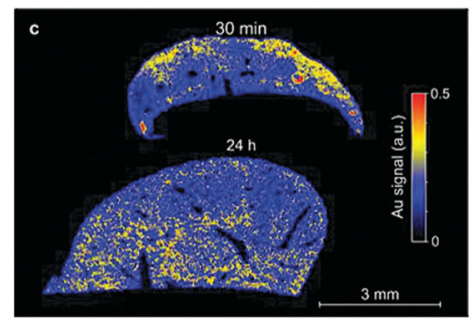

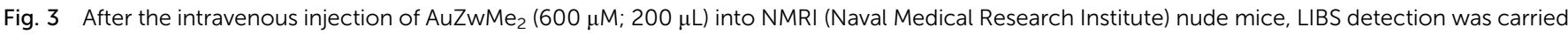

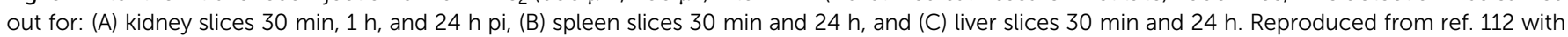
permission from The Royal Society of Chemistry publishing group. 
constant Au signal was observed in the liver and spleen during $24 \mathrm{~h}$ (Fig. 3B and C, respectively). These results were confirmed ex vivo by fluorescence and inductively coupled plasma mass spectrometry measurements.

These two studies demonstrated that ultra-small size $\mathrm{Au}$ NCs have a very rapid renal clearance, but it is important to better understand the different physicochemical parameters that may affect the kinetics and completeness of this renal elimination.

\subsection{Length of the ligand}

Due to the high surface reactivity of NCs, small changes in the ligand have huge impacts on their biodistribution. For example, the liver-to-blood and the kidney-to-blood ratios are decreased 22 and 1.9 times, respectively, when a glycine moiety is added to a cysteine ligand. ${ }^{21}$

X. D. Zhang et al. ${ }^{59}$ synthesized Au NCs with the same core size, but stabilized by different ligands such as SG or BSA. AuSG showed a very efficient renal clearance with $36 \%$ of the NCs excreted into the urine $24 \mathrm{~h}$ pi and only $6 \%$ were remaining in the mouse 28 days pi. In contrast, more than 95\% of AuBSA were retained 28 days pi, with elevated concentrations in the liver and spleen (Fig. 4A). This difference in terms of pharmacokinetics and biodistribution was attributed to the size of the ligand that changed the HD of the Au NCs. Indeed, the AuSG with its HD of $2 \mathrm{~nm}$ could be taken up by the kidneys, but not the HD of $7 \mathrm{~nm}$ of AuBSA. ${ }^{34,113}$

\subsection{Size of the metal core}

AuSG NPs with increasing metallic core sizes, leading to an increase in their $\operatorname{HD}(2,6$, and $13 \mathrm{~nm})$ were administered intravenously $^{114}$ and, as could be expected, the results indicated that the larger the size, the stronger the liver uptake and the lower the kidney elimination. After one day pi, $50 \%$ of the injected dose (ID) of AuSG with an HD of $2 \mathrm{~nm}$ was eliminated in the urine, while only $4 \%$ or $0.5 \%$ ID for the 6 or $13 \mathrm{~nm}$ ones was observed. On the other hand, $3.7 \%$ ID, $27.1 \%$ ID, and 40.5\% ID were respectively blocked in the liver. This tendency was also confirmed in a study that compared the clearance efficiency of 3.4 and $18.4 \mathrm{~nm}$ large Au NPs stabilized by SG. ${ }^{115}$ However, a reverse size dependency has been observed recently when a sub-nanometer size was reached. $\mathrm{Au}_{25} \mathrm{SG}_{18}$ were filtered faster than $\mathrm{Au}_{18} \mathrm{SG}_{14}$ or $\mathrm{Au}_{10-11} \mathrm{SG}_{10-11}{ }^{46}$ (Fig. 4B). In the latter case, a very small reduction in the number of gold atoms (from 18 to $10-11$ ), and thus a very small reduction in their HD dramatically reduced their renal elimination because of an augmented binding of the clusters on the glomerular glycocalyx.

Accordingly, biodegradable NCs that dissociate into small fragments should also be cleared from the body. CuSG are $2 \mathrm{~nm}$ large NCs (core diameter and $2.7 \mathrm{~nm} \mathrm{HD}$ ) that gradually
A

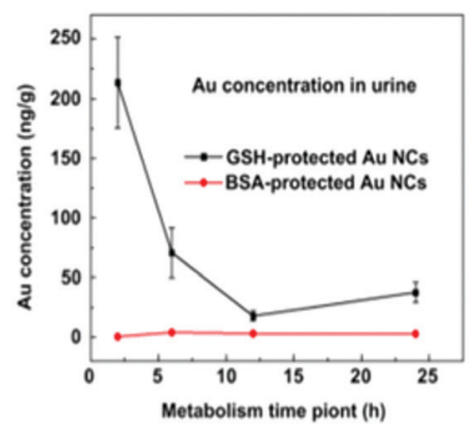

B

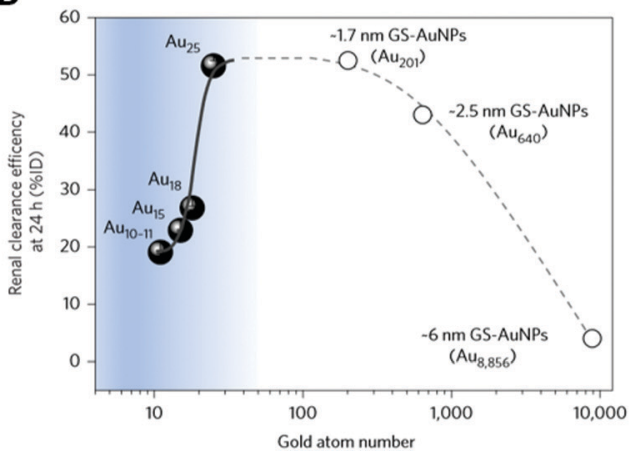

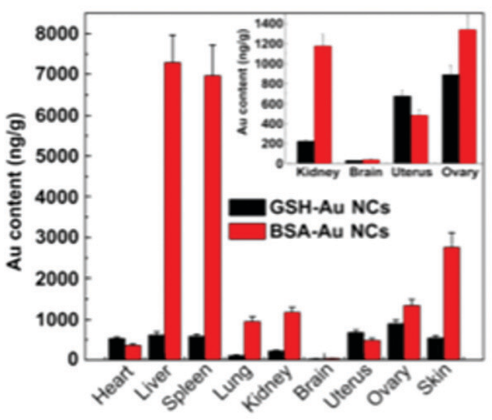

C

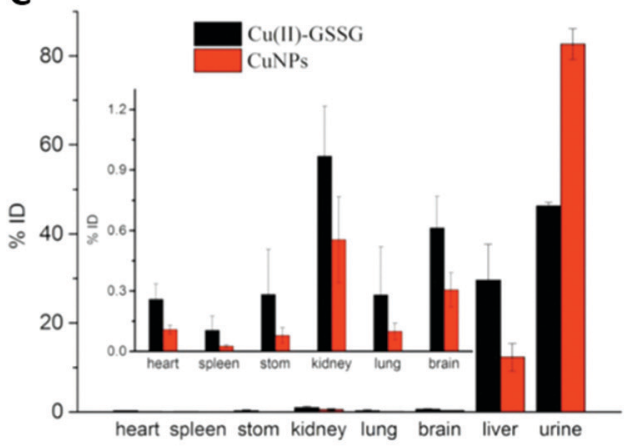

Fig. 4 (A) Renal elimination and biodistribution in mice intravenously injected $\left(7550 \mu \mathrm{g} \mathrm{kg}^{-1}, 151 \mu \mathrm{g} \mathrm{mL}^{-1}\right)$ with AuSG and AuBSA NCs: renal elimination $24 \mathrm{~h} \mathrm{pi} \mathrm{(top} \mathrm{left)} \mathrm{and} \mathrm{biodistribution} \mathrm{in} \mathrm{the} \mathrm{main} \mathrm{organs} 28$ days pi (top right). AuBSA NCs have 10 times higher distribution in the liver and spleen than AuSG NCs. (B) Effect of the sub-nanometer size of the NCs on their renal elimination. Renal elimination efficiencies of different sizes of Au NCs, intravenously injected $(\sim 100 \mu \mathrm{M}, 100 \mu \mathrm{L})$ in BALB/c mice, versus the number of gold atoms at $24 \mathrm{~h}$ pi. The renal elimination increased with the number of gold atoms up to $25\left(\mathrm{Au}_{25} \mathrm{SG}_{18}\right)$ and reached a plateau followed by a decrease for larger sizes. (C) Biodistribution in the main organs $24 \mathrm{~h}$ after intravenous injections of $\mathrm{Cu}(\mathrm{I})$-GSSG complexes ( $300 \mu \mathrm{L}, 0.33 \mathrm{mg} \mathrm{mL}^{-1}$ ) or luminescent CuSG NCs $\left(300 \mu \mathrm{L}, 0.83 \mathrm{mg} \mathrm{mL}^{-1}\right)$ in BALB/c mice $(N=6)$. Reproduced with permission from Elsevier for (A) ref. 59, Springer Nature for (B) ref. 46 and American Chemical Society for (C) ref. 6. 
degrade in $\mathrm{Cu}$ (II)-SG and disulfide (Cu(II)-GSSG) under physiological conditions. ${ }^{6}$ Surprisingly, $90 \%$ of the $\mathrm{Cu}$ collected in the urine $2 \mathrm{~h}$ pi was still in the form of CuSG, while $60 \%$ of $\mathrm{Cu}$ in the liver was in the form of Cu(II)-GSSG-complexes bound to serum proteins. Indeed, CuSG had a higher resistance to serum protein adsorption than $\mathrm{Cu}(\mathrm{II})$-GSSG. This explains why these NCs were quickly eliminated and less accumulated in the liver than the degradation product (Fig. 4C).

\subsection{Protein corona formation}

Proteins can be adsorbed onto the surface of NPs forming the protein corona. ${ }^{113,116}$ The protein coating is a dynamic system with competition between different proteins until an equilibrium is reached. The first layer of proteins is rapidly adsorbed onto the surface of the particles to form the soft corona. In the second step, proteins that have a stronger affinity to the surface of the particles slowly remove the first layer of proteins to generate a stable layer: the hard corona. This means that the composition and thickness of the protein corona evolve with time. ${ }^{117}$ The affinity and exchange rate of the protein corona depend on the size, charge, composition, and shape of the NPs, the incubation conditions (temperature, concentration, and time), the type of proteins, and their stability. ${ }^{116,117}$

The formation of this protein layer will have an impact on cell internalization, bio-distribution, and toxicity of the NPs, ${ }^{118,119}$ and NCs. ${ }^{120}$

Concerning NCs, it was established that incubation of Au NCs with an increasing concentration of human serum albumin (HSA) improved their fluorescence intensity by 6 at high protein concentrations $(3 \mu \mathrm{M}){ }^{121}$ This was probably due to the adsorption of proteins that decreased the non-radiative recombination by forming a rigid protection layer or inducing new metal-ligand interactions.

The surface charge strongly affects the amount and composition of the protein corona. ${ }^{109}$ Indeed, negative NCs interact preferentially with Apolipoprotein ( $\mathrm{Pi}>5.5$ ), whereas positive NCs prefer albumin ( $\mathrm{Pi}<5.5)$, and as a result, positive NCs accumulate in the spleen, lungs, heart, and kidneys, while negatively charged NCs will rather end up in the liver and testis. ${ }^{109}$

Neutral surfaces obtained with PEGylated ligands or with zwitterionic molecules (SG or BSA) do not bind proteins. However, the non-fouling properties observed with zwitterionic systems are $\mathrm{pH}$ and particle curvature dependent. ${ }^{14,55,115}$

\subsection{Density}

The size of a nanoparticle is important, but its density (i.e. mass/ volume) may also have a strong impact. Increasing the density of a NC will augment its interaction with the surface of the blood vessels. NCs stabilized by SG but with different metal cores ( $\mathrm{Au}$, $\mathrm{Ag}$, and $\mathrm{Au} / \mathrm{Ag}$ alloy) were synthesized. ${ }^{122}$ As compared to high density AuSG, the low-density AgSG presented low affinity for the blood vessels, faster clearance, and shorter retention time.

\subsection{Electrical charge}

The charge of the NCs also determines the affinity of the NCs for the blood vessels. AuSG NCs functionalized with ethanediamine or ethanedioic acid to generate positively and negatively charged surfaces were more slowly excreted than neutral NCs over a 90 day period. ${ }^{109}$ Just $24 \mathrm{~h}$ after intraperitoneal administration, the amount of positively charged NCs in the kidneys was two times higher than those of neutral NCs. Various studies have demonstrated that, after glomerular filtration, positively charged compounds bind through their cationic sites to megalin receptors overexpressed on negatively charged proximal tubule epithelial cells. ${ }^{66,67,123}$ This re-absorption phenomenon could explain that small positively charged compounds were slowly excreted by the kidneys.

\subsection{Influence of the concentration of injected Au NCs}

Finally, the concentration of the injected Au NCs also influences their transport by the blood flow. ${ }^{124}$ An interesting twocompartment kidney elimination process was observed for AuSG intravenously injected into mice at nine different concentrations (from 0.15 to $1059 \mathrm{mg} \mathrm{kg}^{-1}$ of body weight). At low concentrations $\left(<15 \mathrm{mg} \mathrm{kg}{ }^{-1}\right.$ ), kidney elimination was constant at $35 \%$ ID. Then, the renal elimination linearly increased with the concentration of NCs. One explanation is that, for small doses, the AuSG could easily cross the blood vessel wall and enter the extravascular space. The reduction in their blood concentration slows down the renal process. At higher concentrations, the Au NCs are strictly confined to the blood vessels, more rapidly transported by the blood flow, and more efficiently eliminated through the kidneys.

\section{Tumor targeting of Au NCs}

If the renal clearance of the NCs is reckoned as highly relevant to reduce their toxicity, these species should still have enough time to circulate in the body in order to accumulate passively and/or specifically in the tumor microenvironment. The growth of a tumor generally induces the formation of new blood vessels with pore sizes between 300 and $1200 \mathrm{~nm}$ and a perturbation of the lymphatic drainage. This allows NP accumulation in cancer tissues at higher concentrations and for a longer time than in normal tissues. This phenomenon is called the Enhanced Permeability and Retention (EPR) effect. Maeda et al. ${ }^{125}$ were one of the first groups who studied the EPR effect in 1986. They discovered that NPs with a size larger than the KFT can circulate in the blood at high concentrations and for longer times (at least $6 \mathrm{~h}$ ) to allow a passive uptake.

\subsection{Passive accumulation of renal-clearable Au NCs by the EPR effect}

Au NCs combine a high renal clearance with surprisingly elevated passive uptake in MCF-7 tumors. ${ }^{30}$ As can be seen in Fig. 5A, AuSG and IRDye $800 \mathrm{CW}$ present a rapid whole-body distribution and a maximum tumor accumulation $40 \mathrm{~min}$ pi. However, $24 \mathrm{~h} \mathrm{pi}$, the concentration of NCs in the tumor was 10 times higher than that of IRDye 800CW (Fig. 5B). This augmented EPR effect probably occurred because AuSG NCs have a longer blood elimination halflife $\left(t_{1 / 2 \beta}\right)$ than IRDye (Fig. 5C). 
A

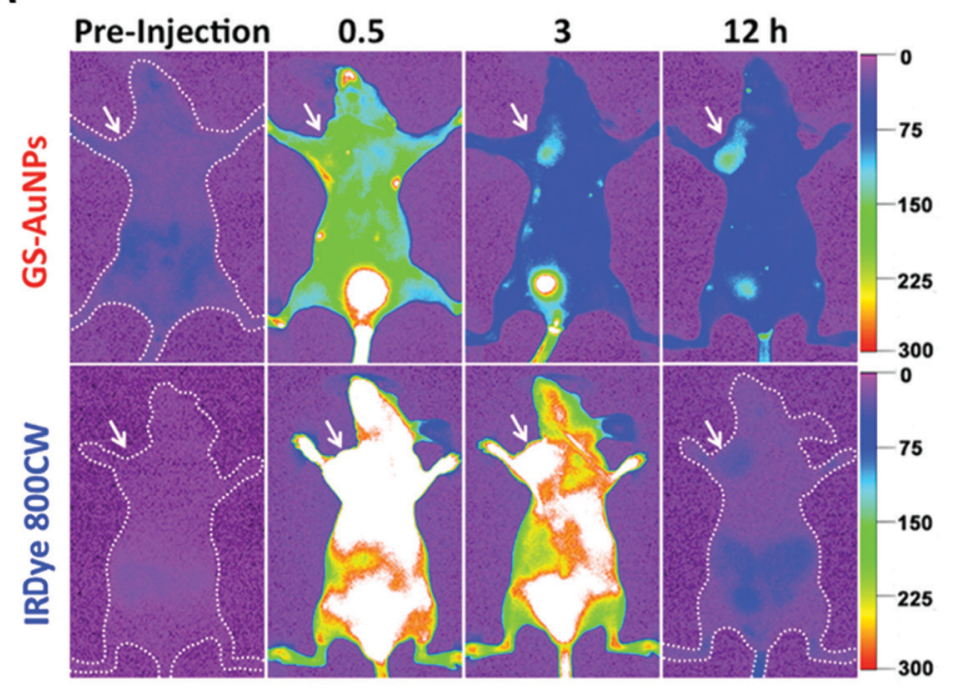

B

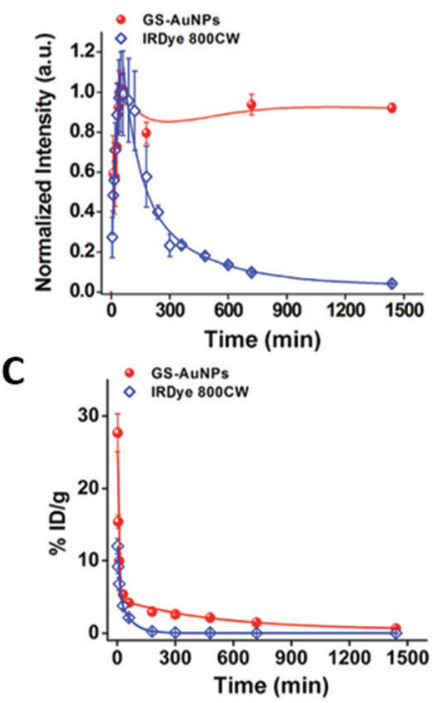

Fig. 5 Tumor uptake and renal elimination in mice intravenously injected with AuSG NCs and IRDye 800CW. (A) In vivo NIR fluorescence images of MCF-7 tumor-bearing mice $0.5,3$, and $12 \mathrm{~h}$ after intravenous injection of AuSG NCs and IRDye $800 \mathrm{CW}\left(200 \mu \mathrm{L}\right.$ at $20 \mathrm{mg} \mathrm{mL}^{-1}$ and $10 \mu \mathrm{M}$, respectively). The tumor areas are indicated by arrows. (B) MCF-7 tumor uptake of AuSG NCs and IRDye $800 \mathrm{CW} 24 \mathrm{~h}$ pi. (C) Renal elimination of AuSG and IRDye $800 \mathrm{CW}$, intravenously injected $\left(200 \mu \mathrm{L}\right.$ at $7 \mathrm{mg} \mathrm{mL}^{-1}$ and $10 \mathrm{mM}$, respectively) at $24 \mathrm{~h}$ pi. The curves were fitted to a biexponential function with $R 2$ values of 0.9711 and 0.9838 , respectively. The distribution half-life $\left(t_{1 / 2 \alpha}\right)$ values are $5.4 \pm 1.2$ and $6.3 \pm 2.5$ min, respectively, and the $t_{1 / 2 \beta}$ values are $8.5 \pm 2.1$ and $0.98 \pm 0.08 \mathrm{~h}$, respectively, for AuSG NCs and IRDye 800CW $(n=3)$. Reproduced from ref. 30 with permission from the American Chemical Society.

Compared to larger Au NPs that are not cleared by the kidneys, AuSG NCs present a two times higher tumor accumulation. This could be attributed to the 10 times lower accumulation of AuSG in the RES compared with Au NPs, which also maintained the highest NC concentration in the blood during the first hours. This implies that NCs escaping RES uptake and remaining long enough in circulation in the blood stream will have a better chance to accumulate in tumors via the EPR effect.

4.1.1 Increasing the circulation time by reducing $\mathrm{Au}$ NC elimination by the kidneys. Au NCs stabilized with SG or PEG ligands with close HD (3.3 and $5.5 \mathrm{~nm}$, respectively) were tested $^{14}$ in order to study the impact of the ligand on renal elimination and tumor targeting. Both NCs were excreted to a similar extent at $24 \mathrm{~h}$ pi in the urine, but their kinetics of elimination were different. The fluorescence intensity of the bladder reached a maximum at $1 \mathrm{~h}$ for the AuSG, while it took $5 \mathrm{~h}$ for the AuPEG. It was thus not surprising that AuPEG showed a tumor accumulation in MCF-7 tumors three times higher than that of AuSG at $12 \mathrm{~h}$ pi. Similar results were obtained with $\mathrm{Au}_{25} \mathrm{SG}_{18}(\sim 1.9 \mathrm{~nm})$ and $\mathrm{AuZwMe}_{2}(\sim 2.36 \mathrm{~nm})^{33,112}$ as well as when $\mathrm{Au}_{25} \mathrm{SG}_{18}$ were compared with smaller $\mathrm{Au}_{10-11} \mathrm{SG}_{10-11}$, $\mathrm{Au}_{15} \mathrm{SG}_{13}, \mathrm{Au}_{18} \mathrm{SG}_{14}{ }^{46}$ (Fig. 6). However, increasing the size of $\mathrm{NCs}$ with $\mathrm{Au}_{201}$ and $\mathrm{Au}_{640}$ had no impact on tumor uptake.

Overall, this confirms that increasing the circulation time of the NCs favors their passive uptake by the tumor.

4.1.2 Increasing the cellular interaction. Neutral, positively, or negatively functionalized AuSG will not accumulate equally in tumors. ${ }^{37}$ One day after intra-peritoneal administration, 149, 222, and $320 \mathrm{ng} \mathrm{g}^{-1}$ of Au NCs were measured in U14 tumors for neutral, positive, and negative NCs, respectively. The fact that charged Au NCs show higher tumor accumulation than neutral NCs could be explained by different phenomena. The negatively charged cell membranes favor the adsorption of positively charged NCs, thus augmenting their binding to the cells and internalization. ${ }^{126}$ For the negative ones, the enhancement of the EPR effect is more likely due to the lower protein corona adsorption. ${ }^{127}$

\subsection{Active tumor targeting}

The addition of a targeting agent, usually a small (bio)molecule that could specifically interact with receptors overexpressed at the surface of tumor cells is expected to augment the specific tumor accumulation. Cell surface proteins such as integrins, transferrin, and folate receptors (FRs) are commonly targeted because they are overexpressed in tumors. ${ }^{54,61,64,65,101-103,106,108,128}$

AuBSA functionalized with folic acid (FA) ${ }^{51}$ provided maximum tumor/normal tissue ratios $(\mathrm{T} / \mathrm{N})$ in mice with FR-positive HCT116 tumors two times higher than for negative A549 tumor. The functionalization of AuBSA with hyaluronic acid (HA ${ }^{61}$ (Fig. 7) or Luteinizing hormone-releasing hormone (LHRH) ${ }^{83}$ allowed increasing the tumor accumulation by three compared to the AuBSA.

Grafting an RGD-containing peptide on AuBSA can improve the targeting of human glioblastoma U87MG tumors engrafted in mice. ${ }^{86}$ U87MG cells express integrin $\alpha_{\nu} \beta_{3}$, a cell surface receptor recognized by RGD. If, $1 \mathrm{~h}$ after the intravenous injection of AuBSA, the tumor was detected due to the EPR effect, the signal dramatically decreased after $2 \mathrm{~h}$. In contrast, the NIR fluorescence of the RGD-Au in tumors was still visible after $24 \mathrm{~h}$. Thus, functionalized $\mathrm{Au}$ NCs with a targeting molecule could improve the tumor accumulation of the $\mathrm{Au}$ NCs and prolong their retention time. 
A

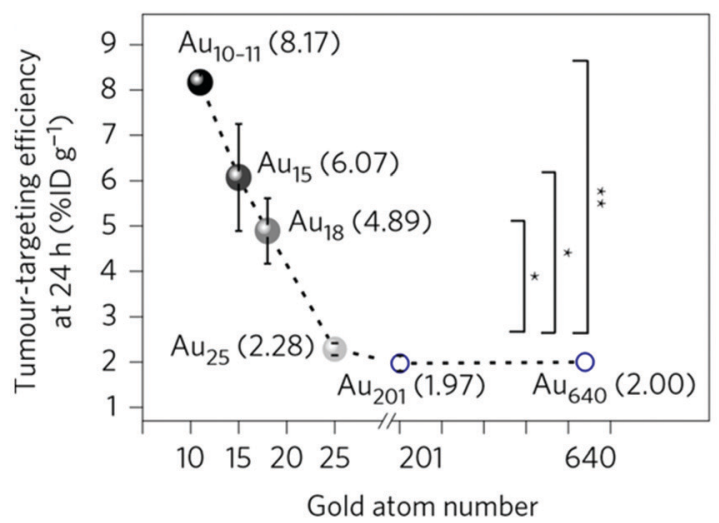

B

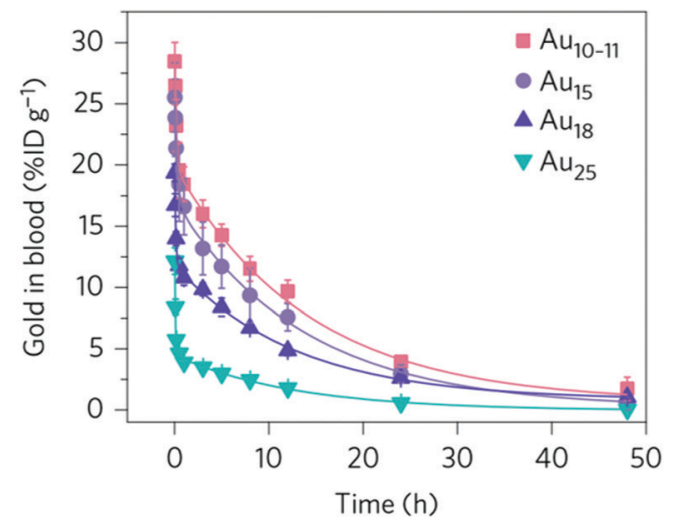

Fig. 6 Effect of the subnanometer size of the NCs on tumor uptake: (A) MCF-7 tumor accumulation efficiency of different-sized Au NCs versus the number of gold atoms at $24 \mathrm{~h}$ p.i. For $\mathrm{NCs}$ smaller than $\mathrm{Au}_{25} \mathrm{SG}_{18}\left(\mathrm{Au}_{10-11} \mathrm{SG}_{10-11}, \mathrm{Au}_{15} \mathrm{SG}_{13}, \mathrm{Au}_{18} \mathrm{SG}_{14}\right)$, the tumor accumulation decreased with increasing number of gold atoms. For $\mathrm{NCs}$ larger than $\mathrm{Au}_{25} \mathrm{SG}_{18}\left(\mathrm{Au}_{201}\right.$ and $\left.\mathrm{Au}_{640}\right)$, tumor uptake was constant. ${ }^{*} P<0.05, * \star P<0.005$, Student's $t$-test. (B) Blood pharmacokinetics of $\mathrm{Au}_{10-11} \mathrm{SG}_{10-11}, \mathrm{Au}_{15} \mathrm{SG}_{13}, \mathrm{Au}_{18} \mathrm{SG}_{14}$, and $\mathrm{Au}_{25} \mathrm{SG}_{18}$ show two-compartment pharmacokinetics with different distributions and $t_{1 / 2 \beta}$ between the NCs. BALB/c mice $(n=3)$ were intravenously injected $(\sim 100 \mu \mathrm{M}, 100 \mu \mathrm{L})$. Reproduced from ref. 46 with permission from Springer Nature publishing group.

A

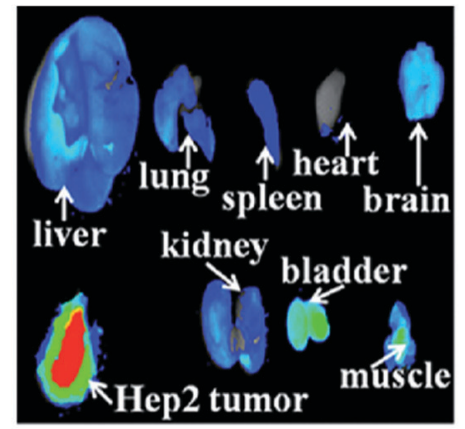

C

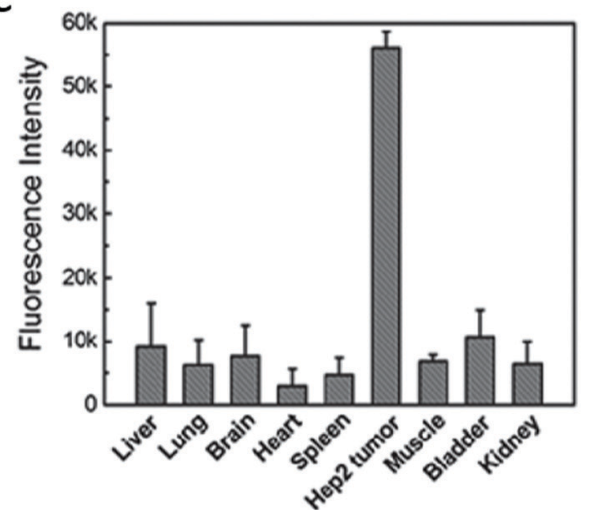

B

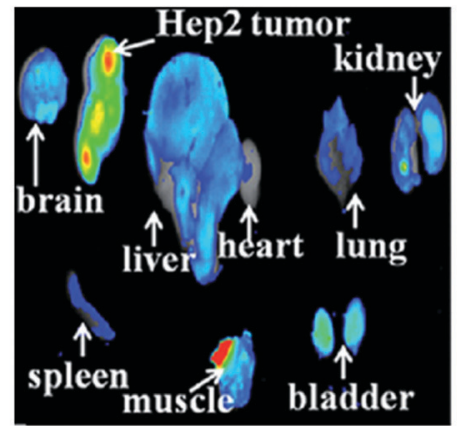

D

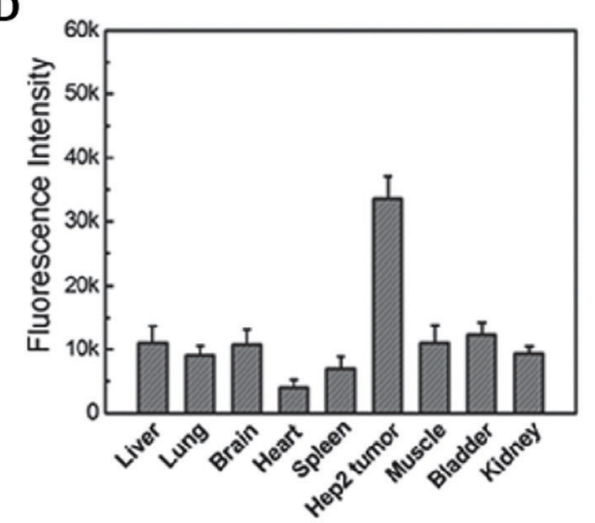

Fig. 7 Ex vivo fluorescence images of the tumor and of the major organs in mice $7 \mathrm{~h}$ p.i. of HA-AuBSA NCs (A) or free HA and AuBSA NCs (B) with the corresponding average fluorescence intensity analysis ( $C$ and D). The addition of the targeting ligand HA grafted onto the Au NC surface improves the tumor uptake by two times. Reproduced from ref. 61 with permission from The Royal Society of Chemistry publishing group.

In another study, a dual targeting was tested. A cRGD peptide and a 26-base G-rich DNA oligonucleotide that functions as a nucleolin-binding aptamer (AS1411) were added to Au NCs to induce a dual targeting. ${ }^{38}$ The nucleolin receptors are overexpressed on the cell membrane of most of the cancer cells. The tumor signal disappeared $8 \mathrm{~h}$ pi when naked Au NCs were used. In contrast, it was still detectable $48 \mathrm{~h}$ later when only one targeting molecule was added. This confirmed the interest of using targeted $\mathrm{Au}$ NCs to augment their retention time in the tumor. If both ligands were co-presented by the Au NCs, the T/N fluorescence ratio was increased to a greater extent (7.2) than when the Au NCs were labeled with only cRGD (5.4). 
If the addition of a targeting agent on the Au NC surface favors higher and longer tumor accumulation, ${ }^{38,103-105,107}$ it also increases the size and changes the charge of the Au NCs, which could be at the expense of their renal elimination.

\section{Au NCs: promising theranostic agents}

Au NCs are useful for multimodal cancer diagnosis and therapy.

\subsection{Multimodal diagnostic applications}

Many imaging techniques are used daily in hospitals for diagnosis, image-guided surgery, and follow-up of treatment efficacy. We will present only imaging techniques that have already been tested with Au NCs in animal models.

5.1.1 Optical imaging. Optical imaging (OI) is a multiscale (from molecules to cells and up to the patient), noninvasive technique $^{129}$ that facilitates real-time ${ }^{79}$ in vivo monitoring with high sensitivity ${ }^{130,131}$ and temporal resolution to visualize dynamic processes. ${ }^{111}$

However, OI also presents drawbacks and in particular suffers from a weak penetration of light in biological tissues, especially because hemoglobin absorbs light below $650 \mathrm{~nm}$ while water will absorb wavelengths above $900 \mathrm{~nm} .{ }^{129,132}$ In addition, in the visible range $( \pm 400-700 \mathrm{~nm})$, auto-fluorescence of some tissues (skin especially) leads to a high background noise that reduces the optical contrast. For all these reasons, it is particularly interesting to work in the NIR wavelength range between 700 and $900 \mathrm{~nm}$, called the "transparent imaging window.",79,129

Au NCs, with their water solubility, biocompatibility, tunable PL from the UV to the NIR, and resistance to photobleaching in contrast to organic fluorophores, are potentially good optical probes. In the earliest works, the low emission wavelength at $480 \mathrm{~nm}$ of $\mathrm{Au}$ NCs stabilized with histidine (His) ${ }^{23}$ limited their use to superficial tissues or cell imaging. A hydrophilic indocyanine green fluorophore needed to be added to have an emission at $800 \mathrm{~nm}$ that can be followed in vivo. In the case of AuBSA, even though the $680 \mathrm{~nm}$ emission ${ }^{58,61,133}$ enabled their detection under few millimeters of tissues, the conjugation with an indocyanine green fluorophore also permitted a shift of the emission in the NIR and facilitated their detection. ${ }^{62}$ As mentioned in the first part, several strategies exist to shift the emission to higher wavelengths and to increase the QY of the NCs for improving their limit of detection. In the meantime, other NCs such as AuSG ${ }^{14,30}$ and $\mathrm{AuPEG}^{14}$ with intrinsic NIR fluorescence were employed.

Seminal works by H. Dai ${ }^{79,132,134}$ have demonstrated the benefit in terms of spatial and temporal resolutions to move from the NIR to a SWIR spectral window with the parallel development of new contrast agents and camera. ${ }^{79} \mathrm{LA}$-sulfobetainecapped $\mathrm{Au}$ NCs with relatively good fluorescence in the NIR/SWIR region (QY of $0.6 \%$ at $1000 \mathrm{~nm}$ and $3.8 \%$ at $900 \mathrm{~nm}$ ) and broad emission were produced. ${ }^{78}$ After their intravenous injection, images of the blood vessels were obtained with higher contrast and spatial resolution in the SWIR using a long-pass filter at $1250 \mathrm{~nm}$ than in the NIR.

$\mathrm{Au}$ NCs thus appeared as new promising SWIR (Fig. 8A) and NIR (Fig. 8B) contrast agents.

5.1.2 X-ray CT. X-ray CT is also a noninvasive technique ${ }^{31}$ with a high $3 \mathrm{D}$ resolution that offers anatomical information, but suffers from low sensitivity. ${ }^{31,131,136,137}$ An additional contrast agent is often required to distinguish soft tissues. ${ }^{31,137}$ Iodine and gold are used as X-ray contrast agents; ${ }^{31,52,137,138}$ however, the short circulation time, nonspecific distribution, and potential renal toxicity of iodine limit its application. The idea is to find a compound slightly larger to increase the circulation time: Au NCs satisfy this criterion. ${ }^{114}$

AuBSA were thus tested in mice, allowing an improved visualization of the structure of major organs (heart, liver, kidneys, bladder, and intestine) and a clear delineation of the calyces, pelvis, ureters, and bladder (Fig. 8C) making AuBSA NC a promising candidate to study renal excretion. ${ }^{31}$ Other NCs such as AuSG were also successfully tested. ${ }^{32}$

Because the Au NCs are also fluorescent, they can serve as bi-modal imaging agents. ${ }^{60} \mathrm{X}$-ray CT images provide anatomical information, but can also be used to confirm the results obtained by optical imaging, such as tumor uptake ${ }^{139}$ or renal elimination of AuSG. ${ }^{32,35,36,114}$

5.1.3 Photoacoustic. Au NCs have recently been employed in photoacoustic imaging ${ }^{140}$ and $\mathrm{OI}^{33}$ (Fig. 8D). AuZw with different metal core sizes and ligand thicknesses were produced, in order to investigate the influence of the metal/ligand ratio on their optical and photoacoustic properties. When the amount of ligand increased, the shell became more rigid, which decreased the nonradiative loss due to vibrations of the ligand. This was associated with an increased fluorescence but decreased photoacoustic signal. However, by decreasing the quantity of ligand, the core of the NCs became larger. Upon illumination, the metallic core produced more heat, which generated more intense vibrations and ultimately improved the photoacoustic signal. Because of this opposite evolution in the signal, Au NCs should be carefully chosen, depending on the technique that will be required for the experiment.

5.1.4 Magnetic resonance imaging. Magnetic resonance imaging (MRI) is a noninvasive technique ${ }^{141}$ largely employed in hospital and clinical settings based on the observation of water's protons contained in the organism when an external magnetic field is applied. This technique allows $3 \mathrm{D}$ reconstruction ${ }^{131,141}$ with high spatial resolution, ${ }^{137,141}$ but suffers from low sensitivity. ${ }^{131,137,141}$ Gadolinium $\left(\mathrm{Gd}^{3+}\right)$ is often used as a contrast agent for MRI detection. ${ }^{107,135,142}$

The use of Au NCs decorated with $\mathrm{Gd}^{3+}$ ions compared to traditional Gd chelates (diethylenetriamine penta-acetic acid, DTPA) improved the performance of Gd as a MRI contrast agent itself and prolonged its detection time three-fold ${ }^{135}$ (Fig. 8E). These Au NCs were still visible by X-ray CT or optical imaging techniques which permit visualization of the organs, where MRI had a weak signal-to-noise ratio, making Gd-functionalized $\mathrm{Au}$ NCs promising tools for tri-modal imaging: MIR/X-ray CT/optical imaging. 
A
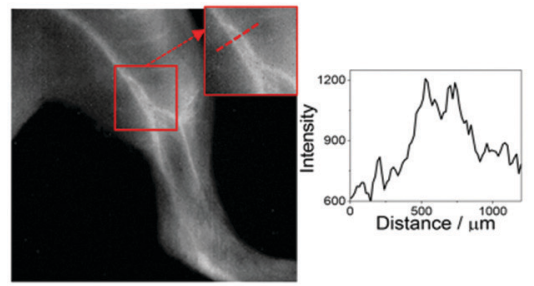

D

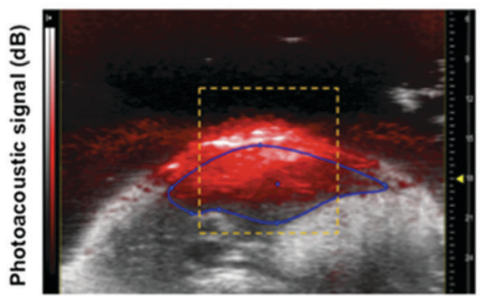

B

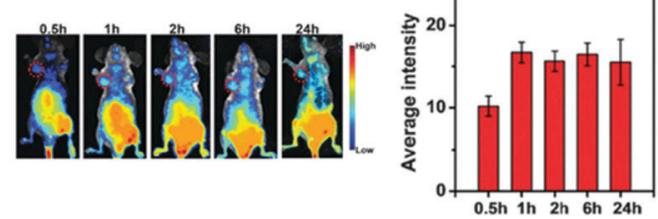

E

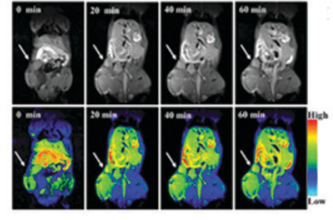

C

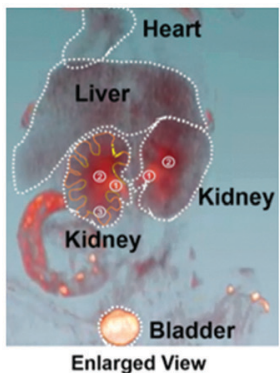

F

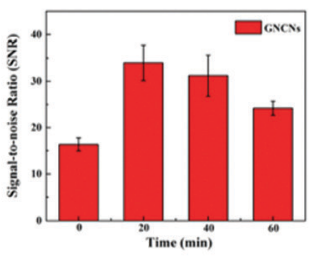

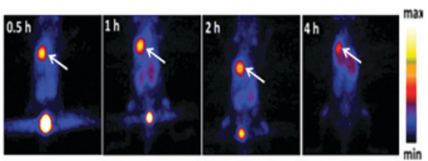

Fig. 8 (A) Image of the left leg of a wild-type CS7BL/6 mouse taken using an InGaAs camera equipped with a 1250 LP filter after the intravenous injection of LA-sulfobetaine-capped Au NCs $(0.5 \mathrm{mg}$ of Au). Signal intensity across a line of interest drawn in the inset images showed the spatial resolution of the vessels. (B) In vivo fluorescence images of a HeLa tumor-bearing nude mouse at different time points (30 min, $1 \mathrm{~h}, 2 \mathrm{~h}, 6 \mathrm{~h}$, and $24 \mathrm{~h}$ ) after intravenous injection of CRGD-Au NCs $\left(200 \mu \mathrm{L}, 8.0 \mathrm{mg} \mathrm{mL}^{-1}\right)$. Red circles indicate the tumor. Quantification of the signal intensity of the tumor side $(n=3)$. (C) In vivo 3D CT images of the heart, liver, kidneys, and bladder (excluding bone) in mice $2 \mathrm{~h}$ after intravenous injection of AuBSA NCs (200 $\mu \mathrm{L}, 9.5 \mathrm{mgAu}$ per $\mathrm{mL}$ ). The ureter, renal pelvis, and the major calyx are marked in orange and yellow dashed curves. (D) Noninvasive in vivo photoacoustic imaging of the belly of a NMRI nude mouse, $3 \mathrm{~h}$ after intravenous injection of AuZw NCs $(200 \mu \mathrm{L}, 600 \mu \mathrm{M})$. (E) In vivo T1-weighted MR images of A549 tumor in a BALB/C-nude mouse at different time points $(20,30$, and $40 \mathrm{~min})$ after intratumoral injection of Gd-AuSG NCs $(50 \mu \mathrm{L}, 0.11 \mathrm{M})$. White arrows indicate the position of the tumor. The graph represents the signal-to-noise ratio around the tumor $(n=3)$. (F) Representative PET images of coronal single slices of an orthotopic A549 lung tumor-bearing mouse at different time points $(0.5,1,2$, and $4 \mathrm{~h}$ ), after intravenous injection of 6.7 MBq of [64Cu]CuNC@BSA-LHRH. White arrows indicate the position of the tumor. Reproduced with permission from American Chemical Society for (A) ref. 78, (C) ref. 31 and (F) ref. 104; The Royal Society of Chemistry for (B) ref. 106, AIP for (D) ref. 33 and Elsevier for (E) ref. 135.

5.1.5 Positron emission tomography. The last noninvasive imaging method described with Au NCs is positron-enhanced tomography (PET). PET has the highest detection sensitivity in human $^{39,143}$ but a poor spatial resolution. ${ }^{131}$

${ }^{64} \mathrm{Cu}$, a well-known $\beta^{+}$radioisotope, is generally complexed with bifunctional chelates, such as DOTA (1,4,7,10-tetraazacyclododecane-1,4,7,10-tetraacetic acid) and TETA (1,4,8,11tetraazacyclododecane1,4,8,11-tetraacetic acid). However, these complexes suffer from low stability, and the released copper ions will be complexed with proteins to be finally stored in the liver. This could induce toxic effects. ${ }^{104}$

The direct incorporation of ${ }^{64} \mathrm{Cu}$ in NCs may overcome these limitations and the ligand shell could favor the radiolabeling stability (Fig. 8F). These NCs keep their initial properties, which means renal excretion and the ability to escape the RES. 6,104

For example, CuSG NCs are progressively degraded into $\mathrm{Cu}(\mathrm{II})$-GSSG. ${ }^{6}$ Due to their interaction with serum proteins, they were then retained in the liver. After intravenous injection in mice, CuSG or Cu(II)-GSSG showed $t_{1 / 2 \beta}$ of 3.2 and $4.9 \mathrm{~h}$, respectively. The successful addition of ${ }^{64} \mathrm{Cu}$, with its halftime of decay of $12.7 \mathrm{~h}$, helped in following the elimination of CuSG with precision. Indeed, the strong signal from the kidneys and the bladder just $1.5 \mathrm{~min}$ pi confirmed the fast renal elimination of $\left[{ }^{64} \mathrm{Cu}\right] \mathrm{CuSG}$. The signal from the bladder still visible $4 \mathrm{~h}$ pi attested the constant elimination of the NCs from the body. Finally, at $4 \mathrm{~h}$ pi, the signal detected in the liver confirmed the dissociation of CuSG into Cu(II)-GSSG complexes.

Radioactive NCs can thus be used for dual imaging. PET offers more sensitive and quantitative follow-up, which will be an addition to the benefits of optical imaging. ${ }^{104,144}$

\subsection{Therapy}

In addition to their use in diagnostics, Au NCs can be used as therapeutic agents and delivery systems.

5.2.1 Radiotherapy. Gold can serve as a radiosensitizer ${ }^{34-36}$ if it is formulated to be biocompatible, to have an efficient renal clearance and good tumor accumulation capability.

Zhang et al. ${ }^{35}$ first studied the potential of a $\mathrm{Au}_{10-12} \mathrm{SG}_{10-12}$ or of a saline solution after intraperitoneal administration $(0.2 \mathrm{~mL}, 3 \mathrm{mM})$ in nude mice engrafted with a human cervical U14 tumor. When the tumor uptake reached a maximum (24 pi), the mice were either irradiated (under ${ }^{137} \mathrm{Cs}$ gamma radiation of $3600 \mathrm{Ci}$ at $5 \mathrm{~Gy}$ ) or not. Regarding the controls, no decrease in tumor size was observed in mice treated with only the $\mathrm{Au}$ NCs over a period of 23 days. In contrast, the tumor volume decreased by $8 \%$ upon irradiation and $65 \%$ with the combination of Au NCs plus irradiation. 
A
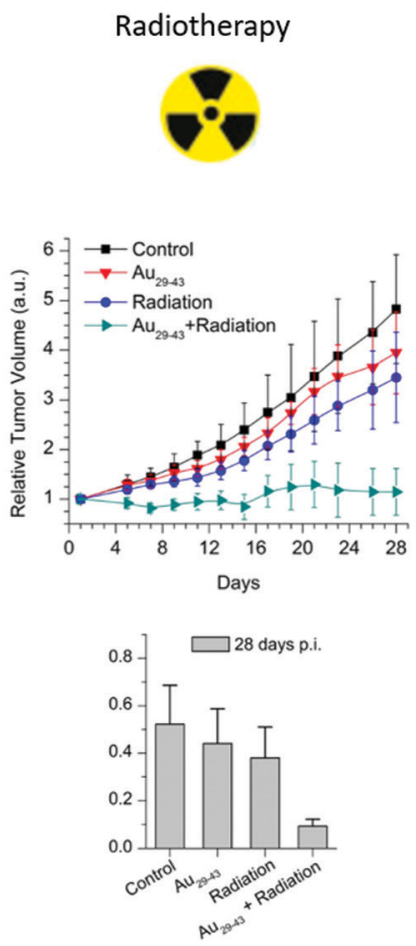

B
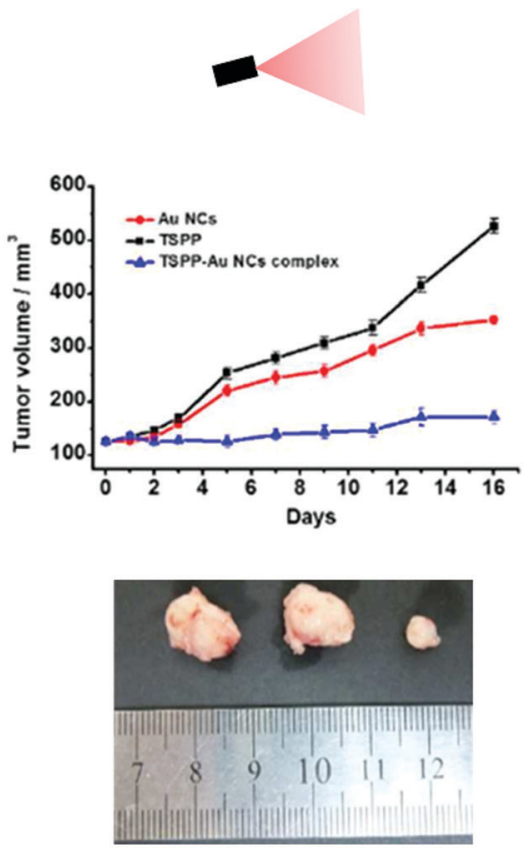

C

Chemotherapy
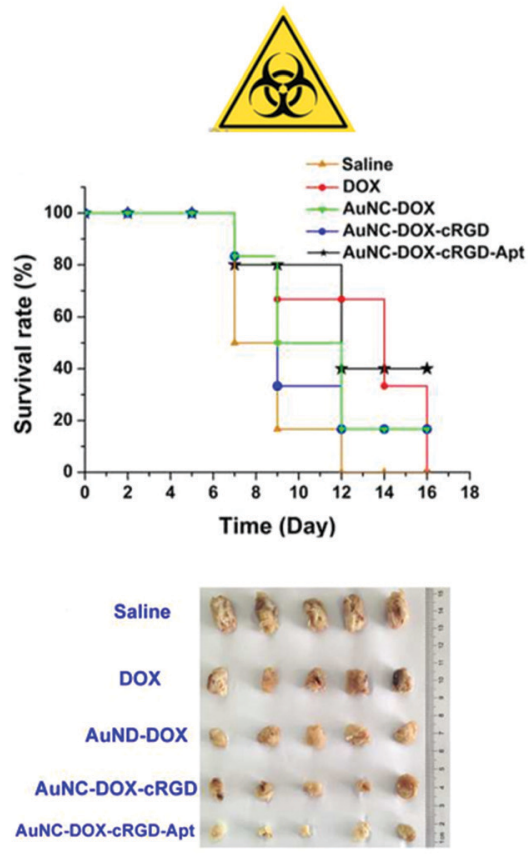

Fig. 9 (A) Time-course studies of the U14 tumor volumes until 28 days pi (top) and measurement of the U14 tumor weights at 28 days pi (bottom) of mice intraperitoneally injected with saline solution (control) or with $\mathrm{Au}_{29-43} \mathrm{SG}_{27-37}(5.9 \mathrm{mgAu}$ per $\mathrm{kg}$ of body), nude mice treated with only radiation (under ${ }^{137} \mathrm{Cs}$ gamma radiation of $3600 \mathrm{Ci}$ at $5 \mathrm{~Gy}, 24 \mathrm{~h}$ pi), and nude mice injected with $\mathrm{Au}_{29-43} \mathrm{SG}_{27-37}$ followed by irradiation ( $n=8$ ). (B) Time-course studies of U87 tumor volumes until 16 days pi (top) of mice intraperitoneally injected with Au NCs (0.1 mL, $5 \mathrm{mM})$, TSPP (0.1 mL, $0.1 \mathrm{mM})$ and TSPP-Au NCs (equivalent $0.1 \mathrm{~mL}, 0.1 \mathrm{mM}$ TSPP) $(n=3)$ and corresponding images isolated from tumor-bearing mice after 16 days of treatment (Au NCs, TSPP and TSPP-Au NCs from left to right, bottom). (C) Survival rate curves of U87MG tumor-bearing mice intravenously injected with free DOX, DOX-Au NCs, CRGD-DOX-Au NCs, and Apt-cRGD-DOX-Au NCs (all at $5.0 \mu \mathrm{g} \mathrm{kg}^{-1}$ equivalent DOX) and corresponding images isolated from tumor-bearing mice after 14 days of treatment (bottom) Reproduced from ref. 36, 38 and 133 with permission from Scientific Reports, The Royal Society of Chemistry and Elsevier publishing group.

The same experiment was carried out with $\mathrm{Au}_{29-43} \mathrm{SG}_{27-37}{ }^{36}$ Compared with the control group, the tumor volume in mice treated with only radiation and mice treated with both $\mathrm{Au}_{29-43} \mathrm{SG}_{27-37}$ and radiation decreased by $10 \%$ and $76 \%$, respectively. No effects were observed in mice injected only with Au NCs (Fig. 9A). In both cases, Au NCs thus generated a toxic effect only if they were irradiated. Similar results were obtained with AuBSA. ${ }^{34}$

5.2.2 Phototherapy. The second well-developed approach in cancer treatment is phototherapy, divided into photo-dynamic therapy (PDT) and photothermal therapy (PTT) but the potential of Au NCs as PTT agents in mice has not yet been proven.

Concerning PDT, $\mathrm{Au}_{25} \mathrm{SG}_{18}$ can generate singlet oxygen species under 650 and $808 \mathrm{~nm}$ irradiation in solution ${ }^{145}$ but most of the current studies use Au NCs combined with photosensitizer molecules such as chlorine $6(\mathrm{Ce} 6)^{37,39,146,147}$ or porphyrin derivatives. $^{37,133}$

Most of the PDT compounds present unwanted cutaneous photosensitivity, and inadequate selectivity that can be ameliorated when combined with NCs. A four-time decrease in the size of C6 tumors was obtained 8 days after the intravenous injection of $\mathrm{Au}$ NCs grafted with protoporphyrin IX, followed by laser treatment $3 \mathrm{~h}$ later $\left.(532 \mathrm{~nm}, 15 \mathrm{~min}, 1.5 \mathrm{~W} \mathrm{~cm})^{-2}\right)^{37}$ compared to the control treated with only radiation. Moreover,
U87 tumor growth can be stopped, after intratumoral injection of Au NCs conjugated with TSPP (meso-tetra(4-sulfonatophenyl)porphine dihydrochloride), a photosensitizer, in U87 tumors, and light excitation for $30 \mathrm{~min}$ per day with IR light indicating that Au NCs can enhance the PDT effect of the photosensitizer alone $^{133}$ (Fig. 9B).

In order to study whether this synergistic effect could be generalized, C. Zhang et al. ${ }^{39}$ intravenously injected Ce6- $\mathrm{Au}_{25} \mathrm{SG}_{18}$, free $\mathrm{Ce} 6$, or PBS into mice with human gastric MGC-803 tumors of $150 \mathrm{~mm} .^{3}$ The tumors were illuminated (633 nm, $10 \mathrm{~min}, 100 \mathrm{~mW} \mathrm{~cm}{ }^{-2}$ ) $8 \mathrm{~h}$ and $24 \mathrm{~h}$ later. After 21 days, the volumes of the tumors for the mice injected with PBS, $\mathrm{Ce} 6$, and $\mathrm{Ce} 6-\mathrm{Au}_{25} \mathrm{SG}_{18}$ without laser treatment were similar and close to $1200 \mathrm{~mm}^{3}$. However, the tumor growth slowed down and reached a volume of around $650 \mathrm{~mm}^{3}$ or $350 \mathrm{~mm}^{3}$, in mice injected with free $\mathrm{Ce} 6$ or $\mathrm{Ce} 6-\mathrm{Au}_{25} \mathrm{SG}_{18}$ followed by illumination. This thus confirmed that $\mathrm{Au}$ NCs can enhance the radiotherapeutic activity of a co-injected radiosensitizer.

Based on this observation, it appeared interesting to generate a core-shell structure using silica ${ }^{146}$ or liposomes ${ }^{147}$ to increase the amount of $\mathrm{Ce} 6$ in contact with the Au NCs. The compounds were intravenously injected into mice with melanoma MDA-MB-435 or breast MDA-MB-361 tumors for compounds with silica or liposome shells, respectively. 
The tumors were irradiated for $10 \mathrm{~min}$ using laser $(671 \mathrm{~nm}$, $100 \mathrm{~mW} \mathrm{~cm}^{-2}$ ) for the silica model and 3 times every 3 days for

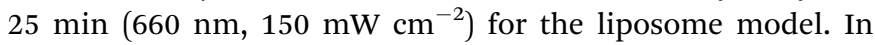
both tumor models, regarding the control, the injection of free Ce6 slowed down the growth of the tumors almost 2 times, while the core-shell structure composed of Ce6 and Au NCs totally inhibited the growth of the tumors. These studies confirmed that Au NCs can enhance the effect of the Ce6 radiosensitizer even after encapsulation in silica or liposomes.

5.2.3 Chemotherapy. Au NCs can also be used for drug delivery, as demonstrated with the delivery of doxorubicin (DOX), a DNA-intercalating agent. ${ }^{38}$ After repeated intravenous administration every $48 \mathrm{~h}$ for 2 weeks, mice with U87MG tumors presented reduced tumor growth with increased necrosis as compared to controls (Fig. 9C).

More complex systems combining multimodal imaging and therapeutic compounds were generated ${ }^{146}$ combining Au NCs functionalized with Ce6 carbon dots. These theranostic agents were usable for fluorescence, MRI and PDT cancer treatments.

To conclude, Au NCs are promising multimodal imaging probes. Due to their intrinsic properties, toxic effects can be generated in the microenvironment of the tumors upon activation by an external stimulus like X-ray radiation or illumination, with reduced damage to healthy tissues. They can be used as therapeutic compounds alone or to enhance the effects of sensitizer agents.

The multimodal properties of the Au NCs make these theranostic agents highly promising in oncology.

5.2.4 Optical-guided surgery. Biocompatible zwitterionic or pegylated ligands containing Au NCs present augmented optical properties and plasma half-life that can improve their passive accumulation in an orthotopic animal model of Head and Neck Squamous Cell Carcinoma (HNSCC). This can serve to detect the presence of tumors in the mouth using non-invasive optical imaging, and can be used intra-operatively by surgeons to perform optical-guided surgery with improved survival rates as compared to standard surgery. Indeed, the presence of fluorescent $\mathrm{Au}$ NC-labeled tumor margins allows the surgeon to better remove all tumor infiltrated surrounding tissues that are not visible by the naked eye, thus reducing the appearance of local relapse. ${ }^{100}$

\section{Conclusions and perspectives}

In this review, we described recent works performed on metal NCs, mainly gold, for in vivo applications. Progress in synthesis methods has enabled the development of effective strategies to produce photoluminescent atomically precise NCs on a large scale, with high purity and different functional groups.

The unique physicochemical properties and good biocompatibility of metal NCs have facilitated their use in biomedical applications. The PL and metallic composition of NCs allow their use as optical or X-ray probes, or radiosensitizers. By integrating $\mathrm{Au}$ NCs with other imaging or therapeutic agents, complex systems could be achieved. These combinations result in powerful image-guided therapy that takes advantage of each

technique. Finally, their fast renal elimination decreases their nonspecific accumulation in different organs, and thus, their toxicity. These optical features combined with their low toxicity and rather simple synthesis method make them very good candidates as contrast agents with respect to other nanomaterials such as Quantum Dots, organic fluorophores, lanthanide NPs, and carbon nanotubes.

Different parameters such as size, length, and charge of the ligands or density affect the formation of the protein corona, optical properties, biodistribution, targeting potential, renal elimination, tumor uptake, and biodegradability of metal NCs. Each of these parameters must be carefully addressed when designing NCs for specific biomedical applications and their possible clinical translation.

$\mathrm{Au}$ NCs have already been applied in vivo on mice and monkeys. ${ }^{124}$ They have shown promising results as theranostic agents, even in parts of the body difficult to access. NCs are not limited to cancer treatments and can be used for diagnosis of other diseases such as renal dysfunctions, ${ }^{31,148,149}$ and Alzheimer's disease. ${ }^{150,151}$

However, some of their properties such as their tumor accumulation and retention or their luminescent properties in the NIR and SWIR regions for in vivo imaging still need to be improved. Further studies are necessary to confirm their radio and photosensitizing effects and more broadly, to get a deeper understanding of the relationships among structure, stability, and luminescence of $\mathrm{Au}$ NCs.

Precise and early diagnosis of tumors and the development of targeted therapies are two major lines of research in oncology. In this context, we believe that photoluminescent Au NCs are promising candidates. Their biomedical potential will go beyond cancer research and toward a wide range of (biomedical) applications (such as fluorophores for fluorescence resonance energy transfer applications, ${ }^{152,153}$ biosensors, and optoelectronics).

Once their pharmacokinetic and luminescence properties, combined with their proven theranostic potential under light or $\mathrm{X}$-ray irradiation, are clearly demonstrated at the preclinical level, we can expect a rapid translation of such ultrasmall Au NCs in clinical trials because of their method of preparation, low toxicity and powerful elimination. In addition, they will benefit from the fact that the Food and Drug Administration has already approved different gold nanoparticles for diagnostics and therapy.

\section{Abbreviations}

BSA

CI

cRGD

DTPA EPR

FA

FR

HA
Bovine serum albumin

Contrast index

Cyclic RGD

Diethylenetriamine penta-acetic acid

Enhancement permeability and retention

Folic acid

Folate receptor

Hyaluronic acid 


$\begin{array}{ll}\text { HD } & \text { Hydrodynamic diameter } \\ \text { H } & \text { Hour } \\ \text { ID } & \text { Injected dose } \\ \text { ID per } g \text {. } & \text { Percentage of injected dose per gram of tissue } \\ \text { KFT } & \text { Kidney filtration threshold } \\ \text { LA } & \text { Lipoic acid } \\ \text { LHRH } & \text { Luteinizing hormone-releasing hormone } \\ \text { LIBS } & \text { Laser induced breakdown spectroscopy } \\ \text { LMCT } & \text { Ligand-to-metal charge transfer } \\ \text { LMMCT } & \text { Ligand-to-metal-metal charge transfer } \\ \text { MRI } & \text { Magnetic resonance imaging } \\ \text { NCs } & \text { Nanoclusters } \\ \text { NIR } & \text { Near-infrared } \\ \text { NPS } & \text { Nanoparticles } \\ \text { PDT } & \text { Photodynamic therapy } \\ \text { PEG } & \text { Polyethylene glycol } \\ \text { PET } & \text { Positron emission tomography } \\ \text { pi } & \text { Post injection } \\ \text { PL } & \text { Photoluminescence } \\ \text { PNA } & \text { Peptide nucleic acid } \\ \text { PTT } & \text { Photothermal therapy } \\ \text { QY } & \text { Quantum yield } \\ \text { ROS } & \text { Reactive oxygen species } \\ \text { RES } & \text { Reticuloendothelial system } \\ \text { SG } & \text { Glutathione } \\ \text { SWIR } & \text { Shortwave infrared } \\ t_{1 / 2} \alpha & \text { Distribution half-life } \\ t_{1 / 2 \beta} & \text { Elimination half-life } \\ \text { UV } & \text { Ultraviolet } \\ \text { X-ray CT } & \text { X-ray computed tomography } \\ \text { Zw } & \text { Zwitterion molecules } \\ & \end{array}$

\section{Conflicts of interest}

There are no conflicts to declare.

\section{Acknowledgements}

We acknowledge the Rhône-Alpes region for the financial support of EP (ARC1 Santé fellowship 2016). We thank Cancéropôle Lyon Auvergne Rhône-Alpes (CLARA), Plan Cancer (C18038CS) and ARC (R17157CC) for financial support. All authors declare that they have no financial/commercial Conflict of Interest.

\section{References}

1 R. Jin, C. Zeng, M. Zhou and Y. Chen, Chem. Rev., 2016, 116, 10346-10413.

2 J. Wang, J. Ye, H. Jiang, S. Gao, W. Ge, Y. Chen, C. Liu, C. Amatore and X. Wang, RSC Adv., 2014, 4, 37790.

3 S. Gao, D. Chen, Q. Li, J. Ye, H. Jiang, C. Amatore and X. Wang, Sci. Rep., 2014, 4, 4384-4390.

4 D. Chen, C. Zhao, J. Ye, Q. Li, X. Liu, M. Su, H. Jiang, C. Amatore, M. Selke and X. Wang, ACS Appl. Mater. Interfaces, 2015, 7, 18163-18169.
5 C. Zhao, L. Lai, F. U. Rehman, C. Qian, G. Teng, H. Jiang and X. Wang, RSC Adv., 2016, 6, 110525-110534.

6 S. Yang, S. Sun, C. Zhou, G. Hao, J. Liu, S. Ramezani, M. Yu, X. Sun and J. Zheng, Bioconjugate Chem., 2015, 26, 511-519.

7 C. J. Ackerson, P. D. Jadzinsky and R. D. Kornberg, J. Am. Chem. Soc., 2005, 127, 6550-6551.

8 F. Aldeek, M. A. H. Muhammed, G. Palui, N. Zhan and H. Mattoussi, ACS Nano, 2013, 7, 2509-2521.

9 X. Yuan, B. Zhang, Z. Luo, Q. Yao, D. T. Leong, N. Yan and J. Xie, Angew. Chem., Int. Ed., 2014, 53, 4623-4627.

10 H.-H. Wang, C.-A. J. Lin, C.-H. Lee, Y.-C. Lin, Y.-M. Tseng, C.-L. Hsieh, C.-H. Chen, C.-H. Tsai, C.-T. Hsieh, J.-L. Shen, W.-H. Chan, W. H. Chang and H.-I. Yeh, ACS Nano, 2011, 5, 4337-4344.

11 L. Shang, N. Azadfar, F. Stockmar, W. Send, V. Trouillet, M. Bruns, D. Gerthsen and G. U. Nienhaus, Small, 2011, 7, 2614-2620.

12 E. Porret, L. Sancey, A. Martín-Serrano, M. I. Montañez, R. Seeman, A. Yahia-Ammar, H. Okuno, F. Gomez, A. Ariza, N. Hildebrandt, J.-B. Fleury, J.-L. Coll and X. Le Guével, Chem. Mater., 2017, 29, 7497-7506.

13 T. D. Fernández, J. R. Pearson, M. P. Leal, M. J. Torres, M. Blanca, C. Mayorga and X. Le Guével, Biomaterials, 2015, 43, 1-12.

14 J. Liu, M. Yu, X. Ning, C. Zhou, S. Yang and J. Zheng, Angew. Chem., Int. Ed., 2013, 52, 12572-12576.

15 E. Oh, F. K. Fatemi, M. Currie, J. B. Delehanty, T. Pons, A. Fragola, S. Lévêque-Fort, R. Goswami, K. Susumu, A. L. Huston and I. L. Medintz, Part. Part. Syst. Charact., 2013, 30, 453-466.

16 H. Duan and S. Nie, J. Am. Chem. Soc., 2007, 129, 2412-2413.

17 J. Zheng, C. Zhang and R. M. Dickson, Phys. Rev. Lett., 2004, 93, 077402-077406.

18 F. Qu, N. B. Li and H. Q. Luo, Anal. Chem., 2012, 84, 10373-10379.

19 J. T. Petty, J. Zheng, N. V. Hud and R. M. Dickson, J. Am. Chem. Soc., 2004, 126, 5207-5212.

20 G. Liu, Y. Shao, K. Ma, Q. Cui, F. Wu and S. Xu, Gold Bull., 2012, 45, 69-74.

21 X. Ning, C. Peng, E. S. Li, J. Xu, R. D. Vinluan, M. Yu and J. Zheng, APL Mater., 2017, 5, 053406.

22 Y. Yu, Z. Luo, Y. Yu, J. Y. Lee and J. Xie, ACS Nano, 2012, 6, 7920-7927.

23 H. Chen, B. Li, C. Wang, X. Zhang, Z. Cheng, X. Dai, R. Zhu and Y. Gu, Nanotechnology, 2013, 24, 055704.

24 Y. Negishi, K. Nobusada and T. Tsukuda, J. Am. Chem. Soc., 2005, 127, 5261-5270.

25 Q. Wen, Y. Gu, L.-J. Tang, R.-Q. Yu and J.-H. Jiang, Anal. Chem., 2013, 85, 11681-11685.

26 R. D. Vinluan, J. Liu, C. Zhou, M. Yu, S. Yang, A. Kumar, S. Sun, A. Dean, X. Sun and J. Zheng, ACS Appl. Mater. Interfaces, 2014, 6, 11829-11833.

27 J. Xie, Y. Zheng and J. Y. Ying, J. Am. Chem. Soc., 2009, 131, 888-889.

28 A. Baksi, P. L. Xavier, K. Chaudhari, N. Goswami, S. K. Pal and T. Pradeep, Nanoscale, 2013, 5, 2009. 
29 X. L. Guével, N. Daum and M. Schneider, Nanotechnology, 2011, 22, 275103.

30 J. Liu, M. Yu, C. Zhou, S. Yang, X. Ning and J. Zheng, J. Am. Chem. Soc., 2013, 135, 4978-4981.

31 Y. Wang, C. Xu, J. Zhai, F. Gao, R. Liu, L. Gao, Y. Zhao, Z. Chai and X. Gao, Anal. Chem., 2015, 87, 343-345.

32 J. Xu, M. Yu, P. Carter, E. Hernandez, A. Dang, P. Kapur, J.-T. Hsieh and J. Zheng, Angew. Chem., Int. Ed., 2017, 56, 13356-13360.

33 D. Shen, M. Henry, V. Trouillet, C. Comby-Zerbino, F. Bertorelle, L. Sancey, R. Antoine, J.-L. Coll, V. Josserand and X. Le Guével, APL Mater., 2017, 5, 053404.

34 X. D. Zhang, J. Chen, Z. Luo, D. Wu, X. Shen, S. S. Song, Y. M. Sun, P. X. Liu, J. Zhao, S. Huo, S. Fan, F. Fan, X. J. Liang and J. Xie, Adv. Healthcare Mater., 2014, 3, 133-141.

35 X. D. Zhang, Z. Luo, J. Chen, X. Shen, S. Song, Y. Sun, S. Fan, F. Fan, D. T. Leong and J. Xie, Adv. Mater., 2014, 26, 4565-4568.

36 X. D. Zhang, Z. Luo, J. Chen, S. Song, X. Yuan, X. Shen, H. Wang, Y. Sun, K. Gao, L. Zhang, S. Fan, D. T. Leong, M. Guo and J. Xie, Sci. Rep., 2015, 5, 8669.

37 L. V. Nair, S. S. Nazeer, R. S. Jayasree and A. Ajayaghosh, ACS Nano, 2015, 9, 5825-5832.

38 D. Chen, B. Li, S. Cai, P. Wang, S. Peng, Y. Sheng, Y. He, Y. Gu and H. Chen, Biomaterials, 2016, 100, 1-16.

39 C. Zhang, C. Li, Y. Liu, J. Zhang, C. Bao, S. Liang, Q. Wang, Y. Yang, H. Fu, K. Wang and D. Cui, Adv. Funct. Mater., 2015, 25, 1314-1325.

40 X.-R. Song, N. Goswami, H.-H. Yang and J. Xie, Analyst, 2016, 141, 3126-3140.

41 Y. Negishi, Y. Takasugi, S. Sato, H. Yao, K. Kimura and T. Tsukuda, J. Am. Chem. Soc., 2004, 126, 6518-6519.

42 Y. Shichibu, Y. Negishi, H. Tsunoyama, M. Kanehara, T. Teranishi and T. Tsukuda, Small, 2007, 3, 835-839.

43 M. A. Habeeb Muhammed and T. Pradeep, Chem. Phys. Lett., 2007, 449, 186-190.

44 R. Jin, H. Qian, Z. Wu, Y. Zhu, M. Zhu, A. Mohanty and N. Garg, J. Phys. Chem. Lett., 2010, 1, 2903-2910.

45 N. Goswami, Q. Yao, T. Chen and J. Xie, Coord. Chem. Rev., 2016, 329, 1-15.

46 B. Du, X. Jiang, A. Das, Q. Zhou, M. Yu, R. Jin and J. Zheng, Nat. Nanotechnol., 2017, 12, 1096-1102.

47 N. Goswami, Q. Yao, Z. Luo, J. Li, T. Chen and J. Xie, J. Phys. Chem. Lett., 2016, 7, 962-975.

48 Q. Yao, T. Chen, X. Yuan and J. Xie, Acc. Chem. Res., 2018, 51, 1338-1348.

49 R. Jin, C. Zeng, M. Zhou and Y. Chen, Chem. Rev., 2016, 116, 10346-10413.

50 M. A. H. Muhammed, F. Aldeek, G. Palui, L. TrapiellaAlfonso and H. Mattoussi, ACS Nano, 2012, 6, 8950-8961.

51 J. Zheng, C. Zhou, M. Yu and J. Liu, Nanoscale, 2012, 4, 4073.

52 J. T. Au, G. Craig, V. Longo, P. Zanzonico, M. Mason, Y. Fong and P. J. Allen, Am. J. Roentgenol., 2013, 200, 1347-1351.

53 A. Ulman, Chem. Rev., 1996, 96, 1533-1554.

54 Y. Wang, C. Dai and X.-P. Yan, Chem. Commun., 2014, 50, 14341-14344.
55 D. F. Moyano, K. Saha, G. Prakash, B. Yan, H. Kong, M. Yazdani and V. M. Rotello, ACS Nano, 2014, 8, 6748-6755.

56 S. Si, R. R. Bhattacharjee, A. Banerjee and T. K. Mandal, Chem. - Eur. J., 2006, 12, 1256-1265.

57 W. Zhang, J. Ye, Y. Zhang, Q. Li, X. Dong, H. Jiang and $\mathrm{X}$. Wang, RSC Adv., 2015, 5, 63821-63826.

$58 \mathrm{X} . \mathrm{Wu}, \mathrm{X} . \mathrm{He}, \mathrm{K}$. Wang, C. Xie, B. Zhou and Z. Qing, Nanoscale, 2010, 2, 2244.

59 X. D. Zhang, D. Wu, X. Shen, P. X. Liu, F. Y. Fan and S. J. Fan, Biomaterials, 2012, 33, 4628-4638.

60 A. Zhang, Y. Tu, S. Qin, Y. Li, J. Zhou, N. Chen, Q. Lu and B. Zhang, J. Colloid Interface Sci., 2012, 372, 239-244.

61 P. Zhang, X. X. Yang, Y. Wang, N. W. Zhao, Z. H. Xiong and C. Z. Huang, Nanoscale, 2014, 6, 2261-2269.

62 H. Chen, B. Li, X. Ren, S. Li, Y. Ma, S. Cui and Y. Gu, Biomaterials, 2012, 33, 8461-8476.

63 X. Le Guével, V. Trouillet, C. Spies, G. Jung and M. Schneider, J. Phys. Chem. C, 2012, 116, 6047-6051.

64 C. Sun, H. Yang, Y. Yuan, X. Tian, L. Wang, Y. Guo, L. Xu, J. Lei, N. Gao, G. J. Anderson, X.-J. Liang, C. Chen, Y. Zhao and G. Nie, J. Am. Chem. Soc., 2011, 133, 8617-8624.

65 Y. Wang, J.-T. Chen and X.-P. Yan, Anal. Chem., 2013, 85, 2529-2535.

66 B. Du, M. Yu and J. Zheng, Nat. Rev. Mater., 2018, 3, 358-374.

67 M. Longmire, P. L. Choyke and H. Kobayashi, Nanomedicine, 2008, 3, 703-717.

68 A. K. Iyer, G. Khaled, J. Fang and H. Maeda, Drug Discovery Today, 2006, 11, 812-818.

69 E. Blanco, H. Shen and M. Ferrari, Nat. Biotechnol., 2015, 33, 941-951.

70 L. Yang, H. Kuang, W. Zhang, Z. P. Aguilar, H. Wei and H. Xu, Sci. Rep., 2017, 7, 3303-3315.

71 E. B. Ehlerding, F. Chen and W. Cai, Adv. Sci., 2016, 3, 1500223.

72 T. S. Hauck, R. E. Anderson, H. C. Fischer, S. Newbigging and W. C. Chan, Small, 2010, 6, 138-144.

73 Y. Sun, W. Feng, P. Yang, C. Huang and F. Li, Chem. Soc. Rev., 2015, 44, 1509-1525.

74 K. Kostarelos, Nat. Biotechnol., 2008, 26, 774-776.

75 Y.-S. Chen, Y.-C. Hung, I. Liau and G. S. Huang, Nanoscale Res. Lett., 2009, 4, 858-864.

76 Y. Huang, L. Fuksman and J. Zheng, Dalton Trans., 2018, 47, 6267-6273.

77 X. L. Guevel, O. Tagit, C. E. Rodríguez, V. Trouillet, M. Pernia Leal and N. Hildebrandt, Nanoscale, 2014, 6, 8091-8099.

78 Y. Chen, D. M. Montana, H. Wei, J. M. Cordero, M. Schneider, X. Le Guével, O. Chen, O. T. Bruns and M. G. Bawendi, Nano Lett., 2017, 17, 6330-6334.

79 G. Hong, A. L. Antaris and H. Dai, Nat. Biomed. Eng., 2017, 1, 0010.

80 R. F. Kubin and A. N. Fletcher, J. Lumin., 1982, 27, 455-462.

81 B. Santiago-González, C. Vázquez-Vázquez, M. C. BlancoVarela, J. M. Gaspar Martinho, J. M. Ramallo-López, F. G. Requejo and M. A. López-Quintela, J. Colloid Interface Sci., 2015, 455, 154-162. 
82 Y.-C. Shiang, C.-C. Huang, W.-Y. Chen, P.-C. Chen and H.-T. Chang, J. Mater. Chem., 2012, 22, 12972.

83 Y. Ma, Y. Zhang and W. W. Yu, J. Mater. Chem. C, 2019, 7, 13662-13679.

84 J.-C. Bünzli, Trends Chem., 2019, 1, 751-762.

85 D. Wu, L. Chen, W. Lee, G. Ko, J. Yin and J. Yoon, Coord. Chem. Rev., 2018, 354, 74-97.

86 S. Link, A. Beeby, S. FitzGerald, M. A. El-Sayed, T. G. Schaaff and R. L. Whetten, J. Phys. Chem. B, 2002, 106, 3410-3415.

87 A. Mooradian, Phys. Rev. Lett., 1969, 22, 185-187.

88 A. Ghosh, T. Udayabhaskararao and T. Pradeep, J. Phys. Chem. Lett., 2012, 3, 1997-2002.

89 Y. Yu, Z. Luo, D. M. Chevrier, D. T. Leong, P. Zhang, D.-E. Jiang and J. Xie, J. Am. Chem. Soc., 2014, 136, 1246-1249.

90 S. Wang, X. Meng, A. Das, T. Li, Y. Song, T. Cao, X. Zhu, M. Zhu and R. Jin, Angew. Chem., Int. Ed., 2014, 53, 2376-2380.

91 X. Le Guével, V. Trouillet, C. Spies, K. Li, T. Laaksonen, D. Auerbach, G. Jung and M. Schneider, Nanoscale, 2012, 4, 7624.

92 E. Oh, J. B. Delehanty, L. D. Field, A. J. Mäkinen, R. Goswami, A. L. Huston and I. L. Medintz, Chem. Mater., 2016, 28, 8676-8688.

93 Z. Wu and R. Jin, Nano Lett., 2010, 10, 2568-2573.

94 G. Wang, R. Guo, G. Kalyuzhny, J.-P. Choi and R. W. Murray, J. Phys. Chem. B, 2006, 110, 20282-20289.

95 K. Pyo, V. D. Thanthirige, K. Kwak, P. Pandurangan, G. Ramakrishna and D. Lee, J. Am. Chem. Soc., 2015, 137, 8244-8250.

96 H.-H. Deng, X.-Q. Shi, F.-F. Wang, H.-P. Peng, A.-L. Liu, X.-H. Xia and W. Chen, Chem. Mater., 2017, 29, 1362-1369.

97 A. Yahia-Ammar, D. Sierra, F. Mérola, N. Hildebrandt and X. Le Guével, ACS Nano, 2016, 10, 2591-2599.

98 Y. Hong, J. W. Y. Lam and B. Z. Tang, Chem. Soc. Rev., 2011, 40, 5361.

99 Z. Luo, X. Yuan, Y. Yu, Q. Zhang, D. T. Leong, J. Y. Lee and J. Xie, J. Am. Chem. Soc., 2012, 134, 16662-16670.

100 C. Colombé, X. Le Guével, A. Martin-Serrano, M. Henry, E. Porret, C. Comby-Zerbino, R. Antoine, I. Atallah, B. Busser, J.-L. Coll, C. A. Righini and L. Sancey, Nanomedicine, 2019, 20, 102011.

101 H. Chen, S. Li, B. Li, X. Ren, S. Li, D. M. Mahounga, S. Cui, Y. Gu and S. Achilefu, Nanoscale, 2012, 4, 6050.

102 K. Pyo, N. H. Ly, S. Y. Yoon, Y. Shen, S. Y. Choi, S. Y. Lee, S.-W. Joo and D. Lee, Adv. Healthcare Mater., 2017, 1700203, DOI: 10.1002/adhm.201700203.

103 D. Chen, Z. Luo, N. Li, J. Y. Lee, J. Xie and J. Lu, Adv. Funct. Mater., 2013, 23, 4324-4331.

104 F. Gao, P. Cai, W. Yang, J. Xue, L. Gao, R. Liu, Y. Wang, Y. Zhao, X. He, L. Zhao, G. Huang, F. Wu, Y. Zhao, Z. Chai and X. Gao, ACS Nano, 2015, 9, 4976-4986.

105 Y. Zhao, L. Detering, D. Sultan, M. L. Cooper, M. You, S. Cho, S. L. Meier, H. Luehmann, G. Sun, M. Rettig, F. Dehdashti, K. L. Wooley, J. F. DiPersio and Y. Liu, ACS Nano, 2016, 10, 5959-5970.
106 X. Wang, H. He, Y. Wang, J. Wang, X. Sun, H. Xu, W. M. Nau, X. Zhang and F. Huang, Chem. Commun., 2016, 52, 9232-9235.

107 S.-K. Sun, L.-X. Dong, Y. Cao, H.-R. Sun and X.-P. Yan, Anal. Chem., 2013, 85, 8436-8441.

108 S. Lucie, G. Elisabeth, F. Stéphanie, S. Guy, H. Amandine, A.-R. Corinne, B. Didier, S. Catherine, G. Alexeï, D. Pascal and C. Jean-Luc, Mol. Ther., 2009, 17, 837-843.

109 J. Y. Wang, J. Chen, J. Yang, H. Wang, X. Shen, Y. M. Sun, M. Guo and X. D. Zhang, Int. J. Nanomed., 2016, 11, 3475-3485.

110 E. S. Shibu, M. A. H. Muhammed, T. Tsukuda and T. Pradeep, J. Phys. Chem. C, 2008, 112, 12168-12176.

111 C. Zhou, G. Hao, P. Thomas, J. Liu, M. Yu, S. Sun, O. K. Öz, X. Sun and J. Zheng, Angew. Chem., 2012, 124, 10265-10269.

112 X. Le Guével, M. Henry, V. Motto-Ros, E. Longo, M. I. Montañez, F. Pelascini, O. de La Rochefoucauld, P. Zeitoun, J.-L. Coll, V. Josserand and L. Sancey, Nanoscale, 2018, 10, 18657-18664.

113 I. Lynch and K. A. Dawson, Nano Today, 2008, 3, 40-47.

114 C. Zhou, M. Long, Y. Qin, X. Sun and J. Zheng, Angew. Chem., Int. Ed., 2011, 50, 3168-3172.

115 C. Peng, X. Gao, J. Xu, B. Du, X. Ning, S. Tang, R. M. Bachoo, M. Yu, W.-P. Ge and J. Zheng, Nano Res., 2017, 10, 1366-1376.

116 C. D. Walkey and W. C. W. Chan, Chem. Soc. Rev., 2012, 41, 2780-2799.

117 P. d. Pino, B. Pelaz, Q. Zhang, P. Maffre, G. U. Nienhaus and W. J. Parak, Mater. Horiz., 2014, 1, 301-313.

118 P. Aggarwal, J. B. Hall, C. B. McLeland, M. A. Dobrovolskaia and S. E. McNeil, Adv. Drug Delivery Rev., 2009, 61, 428-437.

119 R. D. Vinluan and J. Zheng, Nanomedicine, 2015, 10, 2781-2794.

120 L. Shang and G. U. Nienhaus, Int. J. Biochem. Cell Biol., 2016, 75, 175-179.

121 L. Shang, S. Brandholt, F. Stockmar, V. Trouillet, M. Bruns and G. U. Nienhaus, Small, 2012, 8, 661-665.

122 S. Tang, C. Peng, J. Xu, B. Du, Q. Wang, R. D. Vinluan, M. Yu, M. J. Kim and J. Zheng, Angew. Chem., Int. Ed., 2016, 55, 16039-16043.

123 A. Briat, C. H. F. Wenk, M. Ahmadi, M. Claron, D. Boturyn, V. Josserand, P. Dumy, D. Fagret, J.-L. Coll, C. Ghezzi, L. Sancey and J.-P. Vuillez, Cancer Sci., 2012, 103, 1105-1110.

124 J. Xu, M. Yu, C. Peng, P. Carter, J. Tian, X. Ning, Q. Zhou, Q. Tu, G. Zhang, A. Dao, X. Jiang, P. Kapur, J.-T. Hsieh, X. Zhao, P. Liu and J. Zheng, Angew. Chem., 2018, 130, 272-277.

125 J. Fang, H. Nakamura and H. Maeda, Adv. Drug Delivery Rev., 2011, 63, 136-151.

126 E. Koren and V. P. Torchilin, Trends Mol. Med., 2012, 18, 385-393.

127 F. Alexis, E. Pridgen, L. K. Molnar and O. C. Farokhzad, Mol. Pharmaceutics, 2008, 5, 505-515.

128 G. Liang, X. Jin, S. Zhang and D. Xing, Biomaterials, 2017, 144, 95-104.

129 R. Weissleder, Nat. Biotechnol., 2001, 19, 316-317.

130 S. Wang, N. Li, W. Pan and B. Tang, TrAC, Trends Anal. Chem., 2012, 39, 3-37. 
131 S. Lee and X. Chen, Mol. Imaging, 2009, 8, 7290.

132 G. Hong, S. Diao, J. Chang, A. L. Antaris, C. Chen, B. Zhang, S. Zhao, D. N. Atochin, P. L. Huang, K. I. Andreasson, C. J. Kuo and H. Dai, Nat. Photonics, 2014, 8, 723-730.

133 Y. Zhang, J. Li, H. Jiang, C. Zhao and X. Wang, RSC Adv., 2016, 6, 63331-63337.

134 G. Hong, J. C. Lee, J. T. Robinson, U. Raaz, L. Xie, N. F. Huang, J. P. Cooke and H. Dai, Nat. Med., 2012, 18, 1841-1846.

135 W. Hou, F. Xia, G. Alfranca, H. Yan, X. Zhi, Y. Liu, C. Peng, C. Zhang, J. M. de la Fuente and D. Cui, Biomaterials, 2017, 120, 103-114.

136 L. W. Goldman, J. Nucl. Med. Technol., 2007, 35, 115-128.

137 M. F. Kircher and J. K. Willmann, Radiology, 2012, 263, 633-643.

138 J. F. Hainfeld, D. N. Slatkin, T. M. Focella and H. M. Smilowitz, Br. J. Radiol., 2006, 79, 248-253.

139 C. Zhang, Z. Zhou, Q. Qian, G. Gao, C. Li, L. Feng, Q. Wang and D. Cui, J. Mater. Chem. B, 2013, 1, 5045.

140 H. F. Zhang, K. Maslov, G. Stoica and L. V. Wang, Nat. Biotechnol., 2006, 24, 848-851.

141 J.-H. Lee, Y.-M. Huh, Y.-w. Jun, J.-w. Seo, J.-t. Jang, H.-T. Song, S. Kim, E.-J. Cho, H.-G. Yoon, J.-S. Suh and J. Cheon, Nat. Med., 2007, 13, 95-99.

142 G. Liang, D. Ye, X. Zhang, F. Dong, H. Chen, S. Zhang, J. Li, X. Shen and J. Kong, J. Mater. Chem. B, 2013, 1, 3545.
143 S. S. Gambhir, Nat. Rev. Cancer, 2002, 2, 683-693.

144 F. Chen, S. Goel, R. Hernandez, S. A. Graves, S. Shi, R. J. Nickles and W. Cai, Small, 2016, 12, 2775-2782.

145 H. Kawasaki, S. Kumar, G. Li, C. Zeng, D. R. Kauffman, J. Yoshimoto, Y. Iwasaki and R. Jin, Chem. Mater., 2014, 26, 2777-2788.

146 P. Huang, J. Lin, S. Wang, Z. Zhou, Z. Li, Z. Wang, C. Zhang, X. Yue, G. Niu, M. Yang, D. Cui and X. Chen, Biomaterials, 2013, 34, 4643-4654.

147 F. Gao, W. Zheng, L. Gao, P. Cai, R. Liu, Y. Wang, Q. Yuan, Y. Zhao and X. Gao, Adv. Healthcare Mater., 2017, 6, 1601453.

148 M. Zhou, C. Zeng, Y. Chen, S. Zhao, M. Y. Sfeir, M. Zhu and R. Jin, Nat. Commun., 2016, 7, 13240.

149 M. Yu, J. Zhou, B. Du, X. Ning, C. Authement, L. Gandee, P. Kapur, J.-T. Hsieh and J. Zheng, Angew. Chem., Int. Ed., 2016, 55, 2787-2791.

150 L. Lai, C. Zhao, X. Li, X. Liu, H. Jiang, M. Selke and X. Wang, RSC Adv., 2016, 6, 30081-30088.

151 L. Lai, X. Jiang, S. Han, C. Zhao, T. Du, F. U. Rehman, Y. Zheng, X. Li, X. Liu, H. Jiang and X. Wang, Langmuir, 2017, 33, 9018-9024.

152 M. A. H. Muhammed, A. K. Shaw, S. K. Pal and T. Pradeep, J. Phys. Chem. C, 2008, 112, 14324-14330.

153 E. Oh, A. L. Huston, A. Shabaev, A. Efros, M. Currie, K. Susumu, K. Bussmann, R. Goswami, F. K. Fatemi and I. L. Medintz, Sci. Rep., 2016, 6, 35538-35555. 